IFN Working Paper No. 1186, 2017

\title{
Verifying High Quality: Entry for Sale
}

Pehr-Johan Norbäck, Lars Persson and Roger Svensson 


\title{
Verifying High Quality: Entry for Sale*
}

\author{
Pehr-Johan Norbäck \\ Research Institute of Industrial Economics (IFN) \\ Lars Persson \\ Research Institute of Industrial Economics (IFN) and CEPR \\ Roger Svensson \\ Research Institute of Industrial Economics (IFN)
}

October 27, 2017

\begin{abstract}
When and how do entrepreneurs sell their inventions? To address this issue, we develop an endogenous entry-sale asymmetric information oligopoly model. We show that lowquality inventions are sold directly or used for own entry. Inventors who sell post-entry use entry to credibly reveal information on quality. Incumbents are then willing to pay high prices for high-quality inventions to preempt rivals from obtaining them. Using Swedish data on patents granted to small firms and individuals, we find evidence that high-quality inventions are sold under preemptive bidding competition, post entry.

Keywords: Acquisitions, Innovation, Start-ups, Ownership, Patents, Verification, Quality

JEL classification: G24, L1, L2, M13, O3
\end{abstract}

\footnotetext{
${ }^{*}$ We have greatly benefitted from comments from Marcus Asplund, Magnus Henrekson, Jim Levinsohn, Marie Thursby, and participants in seminars at IFN Stockholm Conference, Copenhagen Business School, Tilburg University, University of Mannheim and Royal Institute of Technology (Stockholm). Financial support from the Marianne and Marcus Wallenberg Foundation, the Jan Wallander and Tom Hedelius Foundation and Vinnova are gratefully acknowledged. Email: lars.persson@ifn.se, pehr.johan.norback@ifn.se, roger.svensson@ifn.se.
} 


\section{Introduction}

The key to the successful sale of a business venture is proof of demand. James Caan, a superstar investor known from Dragon's Den, described this as follows: ${ }^{1}$

If you come into a pitch and tell me that you have $x$ amount of buyers already lined up, that automatically increases your chances of investment. You have proved there is a viable market for your idea and for an investor there is nothing better to hear ${ }^{2}$

In his seminal paper, Akerlof (1970) showed that informational asymmetries can give rise to adverse selection in markets, resulting in only low-quality assets being sold. This suggests that entrepreneurs with high-quality inventions will refrain from selling their inventions to incumbents and instead use them to expand their own business. However, as suggested by James Caan, the information asymmetry between the entrepreneur and other economic agents about the quality of the invention can be removed by entry, as the entrepreneur's participation in the product market acts as a credible verification of the quality of her invention. The purpose of this paper is to understand how the possibility of entering the product market, as a means of verification, affects entrepreneurs' mode of commercialization and how this pattern depends on the quality of the invention.

To this end, we develop a model with the following key elements. Consider an entrepreneur who can either directly sell her invention to one of several incumbent firms or enter the product market for the purpose of keeping the invention or selling it post-entry. We assume that incumbents cannot distinguish the true quality of the invention in the pre-entry stage, and thus, the "lemons problem" described in Akerlof (1970) arises: If the entrepreneur has a low-quality invention, she will not be able to generate the amount of revenue needed to cover the cost of product market entry. She may then be tempted to sell the invention to an incumbent preentry, claiming that it is of high quality. Incumbents will realize this incentive and discount their willingness to pay accordingly. This will force entrepreneurs with good inventions to enter the product market, leaving only inventions of low quality for sale in the early acquisition market. However, in our model, entry into the product market can also be used to verify the invention's quality. Using their knowledge of the market, incumbents can infer the quality of the invention post-entry. Indeed, in most developed countries, mandatory disclosure laws and different types of auditing systems have been developed to certify that information about firms' revenues, costs and profits is accurately reported. ${ }^{3}$ Since most high-quality inventions are associated with market power, we model the product market as oligopolistic. This, in turn, implies that entry and a sale of the invention will be associated with externalities being imposed on rival firms. We therefore use an auction with externalities to determine the patterns of ownership of the

\footnotetext{
${ }^{1}$ In the reality TV-show "Dragon's den", entrepreneurs pitch for investment from five business angels (i.e., "Dragons") willing to invest their own money in exchange for equity in the entrepreneur's venture. For details, see http://www.bbc.co.uk/programmes/articles/4nhgBmsXHWDjRqC704jPLyD/about-dragons-den.

${ }^{2}$ The Dragons' Den star's guide to the perfect pitch: James Caan's top tips to win people over to your idea By James Caan for MailOnline.

${ }^{3}$ There is a small literature on costly disclosure and debt financing (see Townsend (1979) and Gale and Hellwig (1985)).
} 
invention in the different parts of the game. We abstract from appropriation problems since the entrepreneur is assumed to have a patent (which is also the case in the data we use below).

We first show that, post-entry, higher invention quality leads to the sale of the invention to an incumbent. The entrepreneur is paid her reservation price (net profit from entry) for inventions with medium quality (so-called entry-deterring acquisitions). For higher invention quality, incumbents bid fiercely for the invention to preempt rivals and get hold of the invention (so-called preemptive acquisitions). This triggers a bidding war among incumbents that drives the sales price substantially higher than the entry profit.

Turning to the pre-entry case and examining the entrepreneur's decision of whether to directly sell the invention, we find that the lemons problem can considerably weaken the incumbents' willingness to pay. Pre-entry, invention quality may then be unrelated or even negatively related to the sale of the invention.

Next, we empirically test our model. We first derive an estimation equation for the entrepreneur's decision to keep or sell her invention post-entry. The estimation equation is derived from a random utility model where the entrepreneur chooses to keep or to sell her invention by comparing the reward from keeping or selling it. Identification exploits that low invention quality leaves the entrepreneur with little or no surplus from a sale, while the bidding competition over high-quality inventions transfers a large share of the surplus to the entrepreneur. We then show that it is only when late acquisitions are preemptive in nature (and not entry-deterring) that higher invention quality translates into an increase in the likelihood of sale. We also derive an estimation equation for the early commercialization or sale decision that allows the entrepreneur to choose among a direct sale, entry or to not commercialize the invention.

In our empirical analysis, we use detailed data on patents granted to Swedish small firms and individual inventors. We have information on 628 patents for which the inventor has ownership stakes in the firm (out of 867 patents in total). The uniqueness of the database is that it contains information on the mode of commercialization of the patent (entry sale/license or no commercialization) and on whether the entrepreneur first entered the market and later sold/licensed the patent (henceforth called "late sale").

The estimates provide evidence for preemptive incumbent acquisitions both in the early stage and in the late stage: Identification stems from the random utility model, which shows that under entry-deterring acquisitions (where the sales price equals the reservation price of the entrepreneur), the estimates should be jointly statistically insignificant. This is rejected by the data. To identify that acquisitions are preemptive, we then proceed to the individual estimates. In the decision to sell early, we find that higher entry costs promote the sale of the invention over entry, while the quality of the invention has no effect on the choice between selling the invention and entering the market (consistent with a lemons problem).

When estimating the decision to sell a patent (invention) post-entry, we find that entry costs have no effect on this decision (as entry costs are sunk at this stage). However, the quality of the invention now has a positive and statistically significant effect on the decision to sell late. The latter result is indeed what our proposed model predicts when late incumbent acquisitions are preemptive in nature.

In sum, we find econometric evidence for entry as a verification device. Costly entry to 
demonstrate initial profits or sales allows entrepreneurs to reveal the quality of the invention to potential buyers. Post-entry, entrepreneurs can then sell high-quality inventions under preemptive bidding competition, securing a significantly higher reward for their innovation efforts.

The paper proceed as follows: Section 2 discusses the paper's relationship to the literature. Section 3 presents some indicative evidence on the entry for verification and sale mechanism. Section 4 presents the theoretical model that we then use to derive an estimation equation for our empirical analyses. In Section 5, we conduct the empirical analysis. Section 6 concludes.

\section{Related literature}

This paper contributes to the literature studying when assets will be sold on the market initiated by Akerlof's (1970) seminal contribution identifying the lemons problem, which means that only low-quality assets will be sold on the market. The empirical literature on the "lemons" effect reports mixed evidence. For instance, Bond (1982) found no evidence, Genesove (1993) weak evidence, and Gilligan (2004) strong evidence of adverse selection. In the context of the entrysale decision, it has been found that commercialization by sale is more likely when entry costs are high, when the entrepreneurial firm lacks complementary assets, when brokers facilitating trade are available, when the expropriation problem associated with asset transfers is low, when the intensity of product market competition is high and when the quality of the invention is high (see, for instance, Anton and Yao (1994), Gans and Stern (2000, 2003) and Gans et al. (2002), Hellmann and Perotti (2011), Norbäck and Persson (2012) and Norbäck et al. (2016). We add to this literature by combining an auction-oligopoly model with an asymmetric information verification model. This enables us to show that entrepreneurs with high-quality inventions have an incentive to enter for sale to sell their high-quality inventions under stiff bidding competition. We also add to this literature by finding empirical evidence that high-quality patents are sold post-entry (whereas low-quality patents are not). Thus our results suggest that the asymmetric information problem in commercialization markets mainly affect the timing of the ownership change and not the ownership identity in the long run. Serrano (2010) explores data on the transfer of U.S. patents and finds that as the importance of the patent (as measured by forward patent citations) increases, the proportion of transferred patents (the sales rate) increases. While our data set is much smaller, these data have the advantage that we have information not only on whether an entrepreneur has sold her patent but also on whether she commercialized the patent on her own. Indeed, it is through the latter information that we can identify patents that are sold under bidding competition.

This paper also contributes to the literature on the timing of sales of ideas and intellectual property. Allain et al. (2015) examine the relationship between market structure and the timing of licensing, which has implications for the efficiency of markets for technology. Jensen et al. (2003) examine faculty members' choice of disclosing their inventions at the proof-of-concept versus the prototype stage and its effects on the terms of licensing. Gans et al. (2008) study how resolving uncertainties over the scope of IP rights affects contractual terms. Luo (2014) examines how the timing of sales depends on how developed an idea is and on the expertise of the seller. Hegde and Lou (2016) examine the effect of the timing of licensing an invention on changes in the disclosure requirements of the American Inventor's Protection Act of 1999 
(AIPA). We add to this literature by showing that high-quality patents are sold under bidding competition in the market but that they are sold post-entry such that the seller can verify the market value of the patent. Moreover, we show that incumbents that turn out to have acquired a failed invention early can temporarily exploit the asymmetric information about the quality of the acquired invention to improve their profitability since uninformed rival incumbents will be less aggressive in the product market interaction.

This paper can finally be seen as a contribution to the literature on auctions with externalities (for an overview, see Jehiel and Moldovanu (2006)). Jehiel, et al. $(1996,1999)$ determine the ownership of assets in an auction with externalities framework. To the best of our knowledge, we provide the first model with empirical support for an auction with externalities.

\section{Indicative evidence for entry for verification and sale}

As a starting point of our entry for verification and sale model, we first present some indicative evidence using our Swedish data on patents and commercialization by small firms and entrepreneurs. Figure 3.1 shows the average number of forward citations, which is our measure of invention quality across different modes of commercialization. The top panel compares three groups:

Group 1: Patents that are not commercialized.

Group 2: Patents where the entrepreneur enters the market (retaining the patent for own use or to sell or licence it at a later stage).

Group 3: Patents that are sold directly or licensed directly (with no change in licensing status).

Patents that are not commercialized (Group 3) have the lowest average number of forward citations (lowest quality). Patents where the inventor enters the product market (Group 2) have the highest average number of average citations (highest quality). Finally, patents that are sold directly (Group 3) have intermediate level of citations.

At first glance, these observations seem to be in line with Akerlof's lemons mechanism: Patents with higher quality do not seem to be sold. However, if we study in greater detail the citation pattern within the group of patents that are initially retained (Group 2), a different picture emerges.

Splitting these patents into a group of patents with maintained entry (Group 2a) and a group of patents that are sold (or licensed) post-entry (Group 2b) reveals that the average number of forward citations in the latter group is approximately two and one-half times larger than that in the former group. Furthermore, comparing panels (i) and (ii) in Figure 3.1 reveals that the group of patents that are sold directly (Group 3) has a lower average number of forward citations than the group of patents that are sold late (Group 2b). Figure 3.1 thus indicates that entrepreneurs sell their best patents post-entry.

The patterns in Figure 3.1 are only indicative. To proceed, we will first examine whether these patterns can be explained in a theoretical model. We then perform a rigorous empirical analysis in Section 5 
(i) Comparing average number of citations between different modes of early commercialization

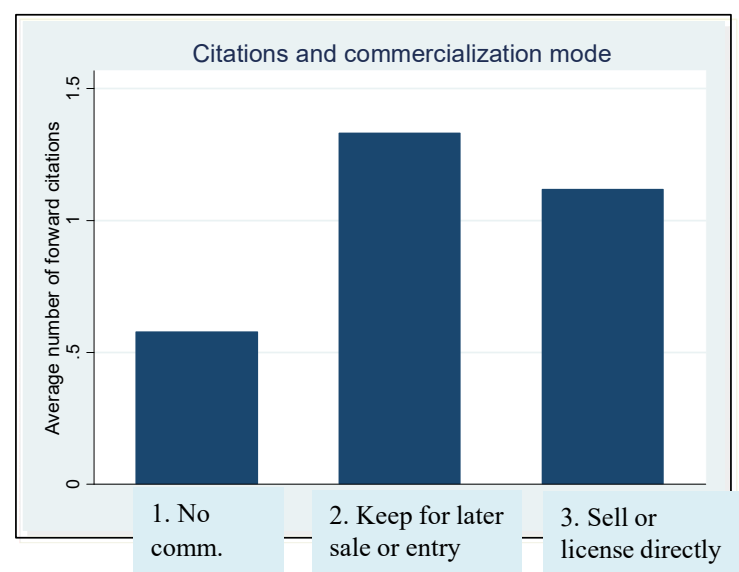

(ii) Comparing average number of citations between different modes of late commercialization

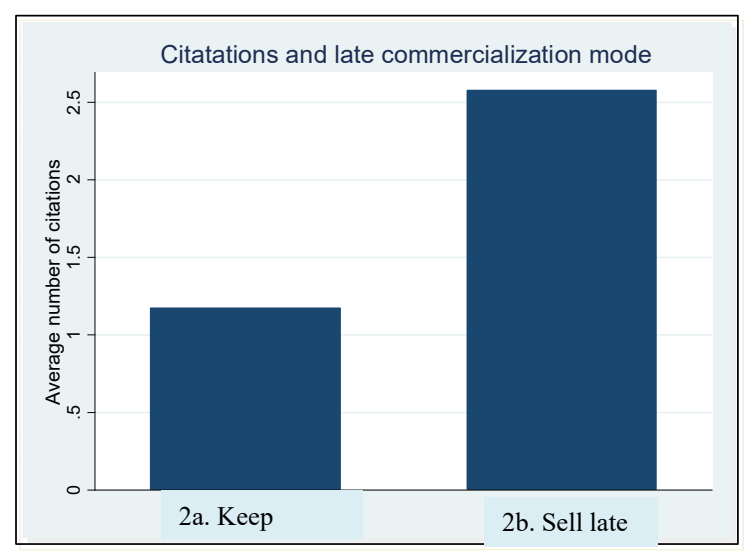

Figure 3.1: The average number of citations across different modes of commercialization. Panel (i) displays early commercialization dividing the patents into patents which are 1.) never commercialized, 2.) used for entry and then either retained for own use or sold or licensed at a later stage, and 3.) sold directly to an incumbent firm. Panel (ii) displays late commercialization dividing the patents into patents which are 2a.) used in maintained entry and 2.b) sold (or licensed) post-entry. 


\section{A model of entry for verification and sale}

Consider an oligopolistic industry with $n$ symmetric firms. Outside this market, there is an entrepreneur, denoted $e$, with an ongoing research project, which may fail or be successful. Only the entrepreneur learns whether the project was a failure $(k=0)$ or a success $(k>0)$. The incumbents know what type of $\mathrm{R} \& \mathrm{D}$ project $(k)$ the entrepreneur is undertaking and assign an exogenous probability of success to the entrepreneur's invention $\theta \in[0,1]$. In stage 1 , the entrepreneur may commercialize the invention into an innovation. She either sells the invention at a first-price imperfect information auction, where the $n$ incumbent firms are the potential buyers, or she keeps the invention and in stage 2 enters the product market at a fixed entry cost $G$, where she competes with incumbents under asymmetric information. In stage 3, she can sell the invention to an incumbent or stay independent. Finally, in stage 4, firms in the product market again compete in an oligopoly, setting an action $x_{i}$.

The following depicts the timing in greater detail:

Stage 1 In the commercialization stage, the entrepreneur can sell the invention under asymmetric information. Incumbents assign a probability of success to the entrepreneur's invention as the prior $\theta$. If an incumbent obtains the invention, only the acquiring incumbent learns the quality of the invention after the purchase. If an incumbent does not obtain the invention, the entrepreneur can decide to enter the market or not commercialize the invention.

Stage 2 In the product market interaction at the beginning of stage 2, information is asymmetric since non-acquiring incumbents can only estimate the quality of the invention from the prior $\theta$. However, at the end of stage 3, profits, costs and output decisions are public information (by law in Sweden and in most other countries), and non-acquiring incumbents can infer the quality of the invention from this information.

Stage 3 Provided that the entrepreneur has entered in stage 1 and competed in the product market in stage 2 , she can then sell the invention under perfect information in this stage. The reason is that the profits generated in stage 2 are public information: From the incumbents' own profits, their rivals' profits and the entrepreneur's profits, incumbents are able to perfectly infer whether the invention is a success or a failure.

Stage 4 Given the mode of commercialization of the invention in stage 1, and the exit stage in stage 3 , firms then compete in the product market under perfect information.

We will solve the model for a perfect Bayesian equilibrium. We use backward induction, starting with the last period, which may be reached by (i) the entrepreneur entering the market in stage 1 and keeping the invention in stage 3; (ii) by the invention being transferred in stage 3 to an incumbent, which uses the invention in the interaction in the product market; (iii) by an early incumbent acquisition in stage 1, where the new owner keeps the invention; or (iv) the invention turns out to have too low quality, in which case it is not used in the ensuing product market interaction. 


\subsection{Stage 4: Product-market equilibrium}

If the invention is commercialized in stage 1 and then used in the product market in stage 3 , firms will then have inferred the true quality of the invention $t=s, f$. (We describe this process in greater detail below.) To encapsulate all the different market structures that may arise from the previous interactions, let the set of potential firms in the industry be $\mathcal{J}=e \cup \mathcal{I}$, where $e$ is the entrepreneur and $\mathcal{I}=\left\{i_{1}, i_{2} \ldots i_{n}\right\}$ is the set of incumbent firms. Denote the owner of the entrepreneur's invention, $k$, by $l \in \mathcal{J}$. In the product market interaction, firm $j$ chooses an action $x_{j} \in R^{+}$to maximize its direct product market profit, $\pi_{j}\left(x_{j}, x_{-j}, l, t\right)$, which depends on its own and its rivals' market actions, $x_{j}$ and $x_{-j}$, the identity of the owner of the invention, $l$, and the quality of the innovation $t=s, f$, where $s=$ success if $k>0$ and $f=$ failure indicates that the innovation failed $k=0$.

We may consider the action $x_{j}$ as setting a quantity or a price. We then assume that there exists a unique Nash equilibrium, $\mathbf{x}^{*}(l, t)=\left(x_{j}^{*}, x_{-j}^{*}\right)$, defined as $\pi_{j}\left(x_{j}^{*}, x_{-j}^{*}: l, k, t\right) \geq$ $\pi_{j}\left(x_{j}, x_{-j}^{*}: l, k, t\right), \forall x_{j} \in R^{+}$, where we assume the product market profits to be positive. Conveniently, this allows us to define a reduced-form product market profit for a firm $j$, taking as given ownership $l$ :

$$
\pi_{j}(l, t) \equiv \pi_{j}\left(x_{j}^{*}(l, t), x_{-j}^{*}(l, t), l, t\right) .
$$

This reduced-form profit function simply summarizes how the invention affects firms' interactions in the product market and how this impacts firms' profits. The assumption that incumbents $i_{1}, i_{2}, \ldots, i_{n}$ are symmetric before the acquisition takes place implies that we need only distinguish between two types of ownership: entrepreneurial ownership $(l=e)$ and incumbent ownership $(l=i)$. Note that there are then three types of firms of which to keep track, $h=\{E, A, N\}$, i.e., the entrepreneurial firm $(E)$, an acquiring incumbent $(A)$ and the non-acquiring incumbents $(N)$.

Let us now define the quality of an invention. Our measure of quality will be in terms of its effect on firms' reduced-form product market profits, $\pi_{h}(l, t)$, in $(4.1)$ :

Definition 1: (Creative destruction) When the quality of the innovation $k$ increases, the profits of the firm in possession of the invention increase, while the profits of its rivals decline: (i) $\frac{d \pi_{A}(i, s)}{d k}>0$, (ii) $\frac{d \pi_{E}(e, s)}{d k}>0$, (iii) $\frac{d \pi_{N}(l, s)}{d k}<0, l=\{e, i\}$ and (iv) $\frac{d \pi_{h}(l, f)}{d k}=0$.

Definition 1 is central and captures Schumpeterian creative destruction: Parts (i) and (ii) thus state that - provided that the innovation is successful - the reduced-form product market profit for the possessor is strictly increasing in the quality of the invention, whereas Part (iii) states that increased quality strictly decreases the rivals' profits. Definition 1 is consistent with a situation in which an invention's impact on profits could be due to either reduced variable costs or increased consumer valuation of the product. These types of effects are present in most standard innovation oligopoly models used in the literature (Gilbert 2006). Part (iv) simply states that reduced-form profits are unaffected if the innovation has failed. If the invention is not commercialized, incumbent profits are $\pi_{N}(0)>0=\pi_{E}(0)$, where the latter inequality simply indicates that if the entrepreneur does not enter the market, she earns no profits.

Using Definition 1 and making the intuitive assumption that profits decline in the number 
of firms, we can then rank firm profits as follows:

$$
\begin{aligned}
& \overbrace{\underbrace{\pi_{A}(i, s)>\pi_{E}(e, s)}_{\text {Market power }}>\pi_{N}(0)>\underbrace{\pi_{N}(i, s)>\pi_{N}(e, s)}_{\text {Market Power }}}^{\text {Creative destruction }}>0=\pi_{E}(0), t=s, \\
& \underbrace{\pi_{N}(0)=\pi_{A}(i, f)=\pi_{N}(i, f)>\pi_{E}(e, f)}_{\text {Market power }}>0=\pi_{E}(0), t=f .
\end{aligned}
$$

In Appendix 7.1, we prove that Definitions 1, (4.2) and (4.3) are fulfilled in a Linear Cournot model where higher invention quality reduces marginal cost.

To make the analysis tractable and focus on the economically more interesting cases, we will assume that the quality $k$ of a successful innovation is not so high that commercialization induces exits. That is, we will assume that the profit of a non-acquiring incumbent is always positive, $\pi_{N}(e, s)>0$. This requires that the invention quality be below a threshold $\bar{k}$. This assumption is not crucial for our results, but it makes the exposition much simpler.

Assumption 1: $k \in(0, \bar{k})$

Initially, the market is also stable with respect to entry with $n$ incumbents. Below, we will derive the lowest threshold on the entry cost $G^{\text {min }}$ such that without a potential invention or with a failed invention (i.e., $k=0$ ), entry is not profitable.

\subsection{Stage 3: "Late sale"}

The commercialization process in stage 3 then is depicted as an auction where $n$ incumbents simultaneously post bids, and the entrepreneur then either accepts or rejects these bids. If the entrepreneur rejects these bids, she will enter the market. Each incumbent announces a bid, $b_{i}$, for the invention. $\mathbf{b}=\left(b_{1}, . . b_{i} . ., b_{n}\right) \in R^{n}$ is the vector of these bids. Following the announcement of $\mathbf{b}$, the invention may be sold to one of the incumbents at the bid price or remain in the ownership of entrepreneur $e$.

We assume that the buyer faces a fixed transaction cost $T$ when acquiring the invention.

There are then three different types valuations of the invention in stage 3 :

- $v_{i e}$ in (4.4) is "entry-deterring valuation"4 . This is the value of obtaining the invention for an incumbent, when the entrepreneur would otherwise keep it. The first term shows the profit when possessing the invention, where $T$ is the transaction cost associated with acquiring it. The second term shows the profit when the entrepreneur keeps the invention.

$$
v_{i e}(t)=\left\{\begin{array}{l}
\pi_{A}(i, s)-T-\pi_{N}(e, s), \text { for } t=s, \\
\pi_{A}(i, f)-T-\pi_{N}(e, f), \text { for } t=f .
\end{array} .\right.
$$

- $v_{i i}$ in (4.5) is the "preemptive valuation". This is the value of obtaining the invention for an incumbent, when a rival incumbent would otherwise obtain it. The first term, again,

\footnotetext{
${ }^{4}$ Labelling this as entry-deterring valuation is somewhat misleading since the entrepreneur has already entered the market. However, it captures the idea that the acquisition prevents lasting entry into the product market.
} 
shows the profit when possessing the invention $k$. The second term is different and shows the profit if a rival incumbent obtains the invention. Note that the market power effect implies that the profit as a non-acquirer is lower when entrepreneur retains the invention than under an acquisition, $\pi_{N}(i, t)>\pi_{N}(e, t)$. Hence, it follows that the entry-deterring valuation exceeds the preemptive valuation, $v_{i e}(t)>v_{i i}(t)$.

$$
v_{i i}(t)=\left\{\begin{array}{c}
\pi_{A}(i, s)-T-\pi_{N}(i, s), \text { for } t=s, \\
-T, \text { for } t=f .
\end{array}\right.
$$

since $\pi_{A}(i, f)=\pi_{N}(i, f)$.

- $v_{e}(t)$ in (4.6) is the "reservation price" for the entrepreneur, or her "entry value". Specifically, it is the value for the entrepreneur of retaining the invention

$$
v_{e}(t)=\left\{\begin{array}{l}
\pi_{E}(e, s), \text { for } t=s \\
\pi_{E}(e, f), \text { for } t=f .
\end{array} .\right.
$$

Selling a successful invention To simplify the presentation and focus on the main mechanism, we will assume that only successful inventions will be sold when invention quality is known. Thus, the value of a failed invention for the incumbents is so low that they will not bid for it.

Formally, we have the following:

Assumption 2 When invention quality is known, incumbent acquisitions of failed inventions to prevent entry are not profitable, $\pi_{A}(i, f)-\pi_{N}(e, f)-T<0$.

From Assumption 2, (4.5) and (4.4), we have

$$
v_{i i}(f)=-T<v_{i e}(f)=\pi_{A}(i, f)-\pi_{N}(e, f)-T<0 .
$$

Let us now turn to the case of a successful invention. We can now define $k^{E D}$ as the invention's quality, where the entry-deterring motive for incumbent acquisition just matches the entrepreneur's reservation price, $v_{i e}(s)=v_{e}(s)$, and $k^{P E}$ as the invention's quality where the preemptive motive for an acquisition by an incumbent is equal to the entrepreneur's entry value, $v_{i i}(s)=v_{e}(s)$.

Following Norbäck, Persson and Svensson (2016), we can then state the following Proposition.

Proposition 1. Suppose that the entrepreneur has succeeded with her innovation in stage 1, $t=s$, entered the market in stage 2 , and competed with incumbents in stage 3 ; then, the revelation of stage-3 profits implies that the quality of the invention is known with certainty by all agents in stage 4 . Then, if $v_{i l, k}^{\prime}(s)>v_{e, k}^{\prime}(s)$, the entrepreneur will retain the invention $\left(l^{*}=e\right)$ if the quality of the invention is sufficiently low, $k \in\left(0, k^{E D}\right)$, (ii) sell it late to an incumbent $\left(l^{*}=i\right)$ at sales price $S^{3^{*}}=v_{e}(s)$ if the quality of the invention is of an intermediate level, $k \in\left[k^{E D}, k^{P E}\right)$, and (iii) sell it late $\left(l^{*}=i\right)$ at sales price $S^{3^{*}}=v_{i i}(s) \geq v_{e}(s)$ if the quality of the invention is sufficiently high, $k \in\left[k^{P E}, \bar{k}\right)$. 
Proposition 1 is important in our analysis: It shows that entrepreneurs will commercialize their best invention by selling it to incumbents and that selling under bidding competition may lead to a significantly higher reward for the entrepreneur than if she had retained the invention in her own firm. In Appendix 7.2, we also prove that Proposition 1 holds in a Linear Cournot model, where higher invention quality reduces marginal costs.

Consider first the case of low quality, $k \in\left(0, k^{E D}\right)$. From Definition 4.1 , the reservation price $v_{e}$ must be increasing in quality since the entrepreneur's profit $\pi_{E}(e, s)$ is increasing in the quality of the invention, i.e.,

$$
v_{e, k}^{\prime}(s)=\frac{d \pi_{E}(e, s)}{d k}>0
$$

where we use the notation $v_{k}^{\prime}(s)=\frac{d v}{d k}$.

What happens when there is a further increase in invention quality? The entry-deterring valuation of an incumbent $v_{i e}(s)$ will increase more than the entrepreneur's value of retaining the invention $v_{e}(s)$ when the quality of the invention increases. To see why, note that the first term in $v_{i e}(s)=\pi_{A}(i, s)-T-\pi_{N A}(e, s)$ increases by a similar amount as the first term in $v_{e}(s)=\pi_{E}(e, s)$. With the profit of a non-acquirer $\pi_{N A}(e)$ declining in invention quality $k$, there must then be an additional increase in the incumbent's entry-deterring valuation, $v_{i e}(s)$. When this negative externality of creative destruction is sufficiently strong, the entry-deterring valuation will increase more strongly than the entrepreneurs' reservation price, i.e.,

$$
v_{i e, k}^{\prime}(s)-v_{e, k}^{\prime}(s)=\left(\frac{d \pi_{A}(i, s)}{d k}-\frac{d \pi_{E}(e, s)}{d k}\right)-\frac{d \pi_{N}(e, s)}{d k}>0
$$

This will trigger an entry-deterring acquisition at the acquisition price $S_{\text {Late }}^{*}=v_{e}(s)$ at $k=k^{E D}$, as shown in panel (ii) of Figure 4.1. Note that other incumbents will not preempt acquisition by a rival in this region $k \in\left[k^{E D}, k^{P E}\right)$, as the preemptive value $v_{i i}(s)$ is lower than the reservation price $v_{e}(s)$. Thus, as shown in panel (ii) of Figure 4.1, the entrepreneur will commercialize by sale $\left(l^{*}=i\right)$ at price $S_{\text {Late }}^{*}=v_{e}(s)$ in this region.

What if the quality of the invention increases even further? This will provoke a preemptive acquisition. A higher invention quality also decreases the profit of a non-acquiring incumbent $\pi_{N A}(i, s)$ when there is an acquisition by an incumbent. If this negative externality is sufficiently strong, an incumbent's preemptive valuation $v_{i i}$ will also increase more in quality than will the reservation price $v_{e}$, i.e.

$$
v_{i i, k}^{\prime}(s)-v_{e, k}^{\prime}(s)=\left(\frac{d \pi_{A}(i, s)}{d k}-\frac{d \pi_{E}(e, s)}{d k}\right)-\frac{d \pi_{N A}(i, s)}{d k}>0 .
$$

As shown in panel (i) in Figure 4.1, when increasing the quality of the invention further than $k^{P E}$, the preemptive valuation $v_{i i}(s)$ becomes strictly higher than the reservation price, $v_{e}(s)$. The creative destruction process now induces a bidding war between incumbents, driving the equilibrium sales price above the profit that the entrepreneur would derive from retaining the invention, $S_{\text {Late }}^{*}=v_{i i}(s)>v_{e}(s)$. The entrepreneur will thus commercialize by sale $\left(l^{*}=\right.$ $i)$, receiving the sales price $S_{\text {Late }}^{*}=v_{i i}(s)$ in the region $k \in\left[k^{P E}, \bar{k}\right)$. In sum, the negative externality associated with a rival acquiring the invention becomes very large when the invention is of high quality. This explains the strong bidding competition and the high sales price. 
(i) Solving for late sale in Stage 3 for a successful invention

(Valuations given entry by the entrepreneur in Stage 1 , followed by her participation in the product market interaction in Stage 2)

(ii) The Equilibrium Ownership Structure (EOS) in Stage 3 for a successful invention

(iii) The equilibrium reward for the entreprenur in stage 3 for a successful invention
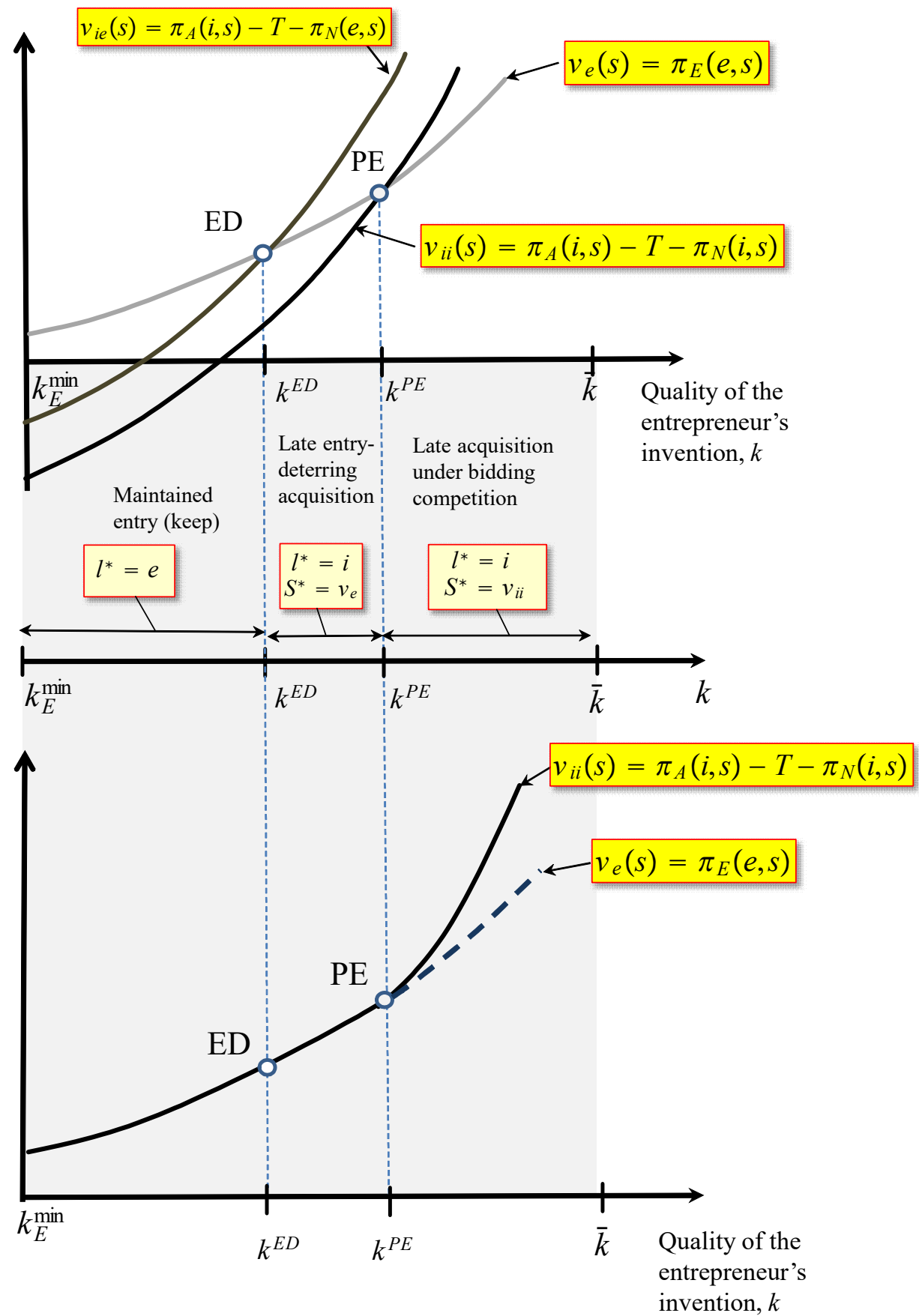

Figure 4.1: The late sale decision: Panel (i) shows how the entrepreneur's mode of commercialization is determined from the incumbent's value of deterring entry by acquiring the entrepreneur's invention $\left(v_{i e}\right)$, the incumbents' value of preempting rivals from acquiring the invention $\left(v_{i i}\right)$, and the entrepreneur's value of pursuing own entry $\left(v_{e}\right)$. Panel (ii) summarizes how the entrepreneur's decision to enter (keep) $\left(l^{*}=e\right)$ or to sell $\left(l^{*}=i\right)$ depends on the quality of the invention, $k$. Panel (ii) also displays the acquisition price $S^{*}$. Panel (iii), finally, displays the reward for the entrepreneur when commercializing the invention. It also shows the premium - or the excess reward over the entry value - that the entrepreneur can attain from selling an invention of very high quality under bidding competition. 


\subsection{Stage 2: Product market interaction under asymmetric information}

Let us now formalize how the verification of quality takes place. Note that only the possessor of the invention (the entrepreneur if she retained the invention in stage 1 and entered the market or the acquiring incumbent if she acquired the invention in stage 1) knows the true quality of the invention. Thus, the product market interaction takes place under asymmetric information. Since no costly action is undertaken by the entrepreneur before any activity takes place in the product market, no new information is revealed to non-acquiring incumbents, and thus, they cannot update their prior $^{5}$. Non-acquiring incumbents only assign a probability $\theta$ that the possessor of the invention has a successful invention and a probability $1-\theta$ that the possessor has a failed invention. The possessor knows how rivals infer the quality of the invention, and rivals know that the possessor knows how they infer the quality of the invention. A possessor $h=A, E$ of an invention of type $t$ then maximizes her direct profit $\pi_{h}\left(x_{h}(t), x_{-h}, l, t\right)$ choosing an action $x_{h}(t)$, given the vector of actions of non-acquiring incumbents, $x_{-h}=\mathbf{x}_{N}$. A nonacquiring incumbent chooses an action $x_{N}$ to maximize her expected profit based on the prior $\theta, \bar{\pi}_{N}$, defined as

$$
\bar{\pi}_{N}=\theta \pi_{N}\left(x_{N}, x_{-N}(s), l, s\right)+(1-\theta) \pi_{N}\left(x_{N}, x_{-N}(f), l, f\right),
$$

where $x_{-N}(s)=\left(x_{h}(s), x_{N}, \ldots, x_{N}\right), x_{-N}(f)=\left(x_{h}(f), x_{N}, \ldots, x_{N}\right)$ are the action of her rivals.

The interaction in the product market then gives rise to a Bayesian Nash equilibrium, written $\mathbf{x}^{*}(l, t, \theta)=\left(x_{h}^{*}(l, s, \theta), x_{h}^{*}(l, f, \theta), \mathbf{x}_{N}^{*}(l, \theta)\right)$, where $x_{h}^{*}(l, s, \theta)$ for $h=A, E$, is the optimal action taken by a possessor of a successful invention, $x_{h}^{*}(l, f, \theta)$ for $h=A, E$ is the optimal action taken by a possessor of a failed invention, and $\mathbf{x}_{N}^{*}(l, \theta)$ is the vector of (symmetric) actions by non-acquiring incumbents (who do not know the true quality $t$ and thus cannot condition their optimal action on the type of invention).

To proceed, let the reduced-form profit for a firm of type $h=\{A, E ; N\}$ be

$$
\pi_{h}(l, t, \theta) \equiv \pi_{h}\left(\mathbf{x}^{*}(l, t, \theta), l, t\right) .
$$

We will make the following assumptions on reduced-form profits, which we prove for the Linear Cournot model in Section 7.3 in the Appendix.

Assumption 3 Let $\theta \in[0,1]$. For $h=A, E$ : (i) $\frac{d \pi_{h}(l, s, \theta)}{d k}>0 \geq \frac{d \pi_{N}(l, s, \theta)}{d k}$, and $\frac{d \pi_{h}(l, f, 0)}{d k}=$ $\frac{d \pi_{N}(l, f, 0)}{d k}=0$, (ii) $\pi_{j}(l, s, \theta)>\pi_{j}(l, f, \theta)>\pi_{N}(l, f, \theta)>\pi_{N}(l, s, \theta)>0, j=A, E$.

Assumption 3(i) implies that Definition 1 holds for a successful invention: If the invention has failed and incumbents are certain that the invention has failed, quality will not affect firms' profits. To ensure that firms assign a positive value to the invention, Assumption 3(ii) states that

\footnotetext{
${ }^{5}$ Note that we assume that the entry cost $G$ is paid in the same period as the product market interaction takes place, stage 3 . If entry took place earlier, i.e., in stage 2 , then product market interaction would take place under perfect information for some parameter values in the model. The reason is that an entrepreneur with a successful medium-to-high-quality invention might then be able to verify success by paying the entry cost $G$. However, we believe that such verification by entry without product market interaction seems difficult to pursue for entrepreneurs in practise. Moreover, for a large set of parameter values of the model, such equilibrium is not possible, and thus, our main mechanism would still be valid.
} 
the possessor of the invention has a higher reduced-form profit when the invention is successful than when it is unsuccessful. In turn, these profits are higher than the profits of a non-acquiring incumbent when the invention has failed, which in turn is higher than the profit of an acquiring incumbent when the invention is successful. Assuming that the latter profit is strictly positive, a non-acquiring incumbent's expected profit $\bar{\pi}_{N}(l, \theta)=\theta \pi_{N}(l, s, \theta)+(1-\theta) \pi_{N}(l, f, \theta)$ is then strictly positive.

Since profits are public information at the end of stage 2, firms can infer the quality of the invention $t=s, f$ from their own or rivals' reduced-form profits $\pi_{h}(l, s, \theta)$, and we can state the following corollary:

Corollary 1. If the invention is commercialized in stage 1, the reduced-form profits in stage 2 reveal the type of the invention.

\subsection{Stage 1: "Early sale": commercialization under asymmetric information}

Let us now solve for the commercialization decision in stage 1 . To determine the firms' valuations in stage 1 , we need take into account how the game proceeds from stages 2 to 4 . There are, again, three types of valuations.

- $w_{e}(t, \theta)$ is the reservation price for the entrepreneur in stage 1 when she has an invention of type $t=\{f, s\}$ and when incumbents have a prior $\theta$ of the invention being successful in the product market interaction in stage 2 .

- $w_{i l}(\theta)$ is the value for an incumbent of buying an invention in stage 1 for which she has a prior of $\theta$ of it being a successful invention when otherwise either the entrepreneur would retain the invention $(l=e)$ or an another incumbent would buy the invention in stage 1 $(l=i)$. Note that only the prior $\theta$ and not the type of invention $t$ is an argument in the incumbents' valuations, $w_{i l}(\theta)$ : This reflects the fact that only the entrepreneur, and not the incumbents, knows the type of the invention in stage 1. Again, these valuations take into account the how the game evolves from stage 1 .

At this point, it is also useful to define the entry-stability condition: This defines the entry cost at which the entrepreneur cannot enter the market with a failed invention or without an invention. Thus, using the notation in (4.1) and (4.12), we note that this entry cost will equal the product market profits that an entrepreneur would obtain when the invention fails, $k=0$, and where incumbents have a zero prior on the entrepreneur succeeding, $\theta=0$.

That is, we have the following assumption:

Assumption 4 Initial Entry-stability: $G \geq G^{\min }=\pi_{E}(e, f, 0)+\pi_{E}(e, f)>0$.

\subsubsection{The entrepreneur's reservation price}

Let the value created from entry in stage 1 , arising from stage- 2 profits, be

$$
v_{e}(t, \theta)=\pi_{E}(e, t, \theta)
$$


Then, from Proposition 1, (4.6) and (4.5), the reservation price in stage 1 for the entrepreneur with a successful invention, $w_{e}(s, \theta)$, is the sum of the value created from stage 2 and onwards net of the entry cost $G$ :

$$
w_{e}(s, \theta)=\left\{\begin{array}{c}
0, \text { for }, v_{e}(s, \theta)-G+\max \left\{v_{e}(s), v_{i i}(s)\right\}<0 \\
v_{e}(s, \theta)-G+v_{e}(s), \text { for } v_{e}(s, \theta)-G+v_{e}(s)>0, k \in\left[0, k^{P E}\right), \\
v_{e}(s, \theta)-G+v_{i i}(s), \text { for } v_{e}(s, \theta)-G+v_{i i}(s)>0, k \in\left[k^{P E}, \bar{k}\right),
\end{array}\right.
$$

where $G$ is paid at the beginning of stage 2 . Note that if the value from entry is negative, the entrepreneur has a zero reservation price, $w_{e}(s, \theta)=0$. Since entry reveals the true quality during the product market interaction in stage 2 , as shown in Corollary 1 , the term $\max \left\{v_{e}(s), v_{i i}(s)\right\}$ is the value from optimally choosing to retain the invention or sell it under full information in stage 3 .

If the entrepreneur has a failed invention, this will also be revealed by the firms' profits in stage 2. Since incumbents have no incentive to buy a failed invention in stage 3 , the entrepreneur's reservation price for a failed invention is simply

$$
w_{e}(f, \theta)=\left\{\begin{array}{c}
0, \text { for } v_{e}(f, \theta)-G+v_{e}(f)<0 \\
v_{e}(f, \theta)-G+v_{e}(f), \text { for } v_{e}(f, \theta)-G+v_{e}(f)>0 .
\end{array}\right.
$$

\subsubsection{Incumbents' valuations}

Incumbents will value the invention according to its expected value, only if the value of deterring commercialization by entry is higher than the reservation price of an entrepreneur with a successful invention, $w_{i e}(\theta)>w_{e}(s, \theta)$. If this condition is not met, incumbents will rationally expect that only failed inventions are for sale, following Akerlof's (1970) classic "lemons problem", and hence, $w_{i e}(\theta)=0$. We now spell out an incumbent's valuations in stage $1 w_{i l}(\theta)$ in greater detail.

The preemptive valuation Suppose first that $w_{i e}(\theta)>w_{e}(s, \theta)$ holds. We can then write the preemptive valuation as the value created from stage 2 and onwards net of the transaction cost $T$ :

$$
\begin{aligned}
w_{i i}(\theta)= & \overbrace{\theta[\underbrace{\pi_{A}(i, s, \theta)-T-\pi_{N}(i, s, \theta)}_{\text {Stage } 1 \text { and } 2}+\underbrace{\pi_{A}(i, s)-\pi_{N}(i, s)}_{\text {Stage } 3 \text { and } 4}]}^{\text {Invention succeeds }}+ \\
& \underbrace{(1-\theta) \underbrace{\left[\pi_{A}(i, f, \theta)-T-\pi_{N}(i, f, \theta)\right.}_{\text {Stage } 1 \text { and } 2}+\underbrace{\left.\pi_{A}(i, f)-\pi_{N}(i, f)\right]}_{\text {Stage } 3 \text { and Stage } 4:}}_{\text {Invention fails }} .
\end{aligned}
$$

The first line shows the expected value of buying a successful invention in stage 1 , with $\theta$ being the prior that incumbents assign to the event that the invention will be successful. The second line shows the value of buying a failed invention, with $1-\theta$ being the probability that incumbents assign to the event that the invention will fail. 
To proceed, let the value for an incumbent from buying the invention in stage 1 generated from stage-2 profits when the invention is of type $t=\{s, f\}$ be

$$
v_{i l}(t, \theta)=\pi_{A}(i, t, \theta)-\pi_{N}(i, t, \theta) .
$$

From (4.5), (4.16) and (4.17) and taking "the lemons problem" into account, we can write incumbent's preemptive valuations in stage 1 as follows:

$$
w_{i i}(\theta)=\left\{\begin{array}{l}
\overbrace{\theta \times\left[v_{i i}(s, \theta)+v_{i i}(s)\right]}^{\text {Invention succeeds }}+\overbrace{(1-\theta) \times\left[v_{i i}(f, \theta)+v_{i i}(f)\right]}^{\text {Invention fails }}, \text { for } w_{i e}(\theta)>w_{e}(s, \theta), \\
0, \text { for } \underbrace{w_{i e}(\theta)<w_{e}(s, \theta)}_{\text {Only failed inventions for sale }} .
\end{array}\right.
$$

since an incumbent will not pay less than the reservation price for a successful invention, rationally inferring that only entrepreneurs with failed inventions would sell if the price were to fall below $w_{e}(s, \theta){ }^{6}$

The entry-deterring valuation Again, first suppose that $w_{i e}(\theta)>w_{e}(s, \theta)$ holds. We can then write the entry-deterring valuation as the value created from stage 2 and onwards net of the transaction cost as follows:

$$
\begin{aligned}
w_{i e}(\theta)= & \overbrace{\theta[\underbrace{\pi_{A}(i, s, \theta)-T-\pi_{N}(e, s, \theta)}_{\text {Stage } 1 \text { and } 2}+\underbrace{\pi_{A}(i, s)-\bar{\Pi}_{N}(s)}_{\text {Stage } 3 \text { and } 4}]}^{\text {Invention succeeds }}+ \\
& \underbrace{(1-\theta) \underbrace{\left[\pi_{A}(i, f, \theta)-T-\pi_{N}(e, f, \theta)\right.}_{\text {Invention fails }}+\underbrace{\left.\pi_{A}(i, f)-\pi_{N}(e, f)\right]}_{\text {Stage } 3 \text { and Stage } 4}}_{\text {Stage } 1 \text { and } 2} .
\end{aligned}
$$

In the first line, $\bar{\Pi}_{N}(s)$ is the net expected profit from stages 3 and 4 when not acquiring a successful invention in stage 1 . In stage 1 , an incumbent knows that in stage 3 she will be the acquirer with probability $1 / n$ and a non-acquirer with probability $(1-1 / n)$. From Proposition 1, (4.6) and (4.5), we then have

$$
\bar{\Pi}_{N}(s)=\left\{\begin{array}{c}
\pi_{N}(e, s), \text { if } k \in\left(0, k^{E D}\right), \\
\pi_{N}(i, s)-\frac{1}{n} \times\left[v_{e}-v_{i i}\right], \text { if } k \in\left[k^{E D}, k^{P E}\right), \\
\pi_{N}(i, s), \text { if } k \in\left[k^{P E}, \bar{k}(e)\right),
\end{array}\right.
$$

where the middle line occurs because the acquiring firm will obtain a lower net profit than will a non-acquiring incumbent, as the buyer pays $S^{3}=v_{e}>v_{i i}$ in stage 3 .

Using (4.5), (4.4) and (4.20), it is convenient to define $\tilde{v}_{i e}(s)$ as the stage-1 value from profits generated in late acquisition stage 3 and the product market interaction under full information

\footnotetext{
${ }^{6}$ We show below that $w_{i e}(\theta)>w_{i i}(\theta)$
} 
in stage 4 , net of the transaction cost $T$ :

$$
\tilde{v}_{i e}(s)=\pi_{A}(i, s)-T-\bar{\Pi}_{N}(s, l)=\left\{\begin{array}{c}
v_{i e}(s), \text { if } k \in\left(0, k^{E D}\right), \\
v_{i i}(s)+\frac{1}{n} \times\left[v_{e}(s)-v_{i i}(s)\right], \text { if } k \in\left[k^{E D}, k^{P E}\right), \\
v_{i i}(s), \text { if } k \in\left[k^{P E}, \bar{k}(e)\right),
\end{array}\right.
$$

where we have exploited that an incumbent knows that buying a successful invention in stage 1 generates a product market profit of $\pi_{A}(i, s)$ in stage 4 , whereas not buying in stage 1 and participating as a bidder in the exit auction in stage 3 gives rise to an expected profit of $\bar{\Pi}_{N}(s, l)$ as defined in (4.20) from the interaction in stages 3 and 4 .

Making use of (4.4) and (4.21) in (4.19) and again taking into account the lemons problem, we can then write an incumbent's entry-deterring valuations in stage 1 as follows:

$$
w_{i e}(\theta)=\left\{\begin{array}{l}
\overbrace{\theta \times\left[v_{i e}(s, \theta)+\tilde{v}_{i e}(s)\right]}^{\text {Invention succeeds }}+\overbrace{(1-\theta) \times\left[v_{i e}(f, \theta)+v_{i e}(f)\right]}^{\text {Invention fails }}, \text { for } w_{i e}(\theta)>w_{e}(s, \theta), \\
0, \text { for } \underbrace{w_{i e}(\theta)<w_{e}(s, \theta)}_{\text {Only failed inventions for sale }} .
\end{array}\right.
$$

\subsubsection{The Equilibrium Ownership Structure (EOS)}

We are now able to solve for the Equilibrium Ownership Structure (EOS), or the equilibrium commercialization pattern in stage 1.

In stage 1 , the entrepreneur knows whether the invention is successful $(t=s$ and $k>0)$ or has failed $(t=f$ and $k=0)$. In contrast, incumbents only know that the invention's potential quality is $k>0$ with probability $\theta$. If an incumbent buys the invention in stage 1 , she will learn the quality after the acquisition, while her rivals will learn the quality from the product market interaction in stage 2. Incumbents will also learn the quality of the invention under entry by the entrepreneur. The product market interaction in stage 2 reveals the quality, which, in turn, sets the stage for the full-information acquisition game in stage 3, where the entrepreneur can sell the invention or retain it and then participate in the product market interaction in stage 4 .

Commercialization of a successful invention $(l=s)$ Consider first Panel (iii) of Figure 4.2 , which depicts the EOS in stage 1 over the $k-G$ space, for a successful invention $(t=s)$. When does the entrepreneur enter the market in stage 1 (for the purpose of maintained entry or late sale), and when does she sell directly?

To answer this, it is first useful to define the Entry Deterring (ED) condition, which shows combinations of invention quality $k$ and entry costs $G$ such that the an incumbent's entrydeterring value of acquiring the invention just matches the entrepreneur's reservation price, $w_{i e}(\theta)=w_{e}(s, \theta)$, and the Preemptive (PE) condition, which shows combinations of invention quality $k$ and entry costs $G$ such that the preemptive value for an incumbent is equal to the entrepreneur's entry value, $w_{i i}(\theta)=w_{e}(s, \theta)$. 


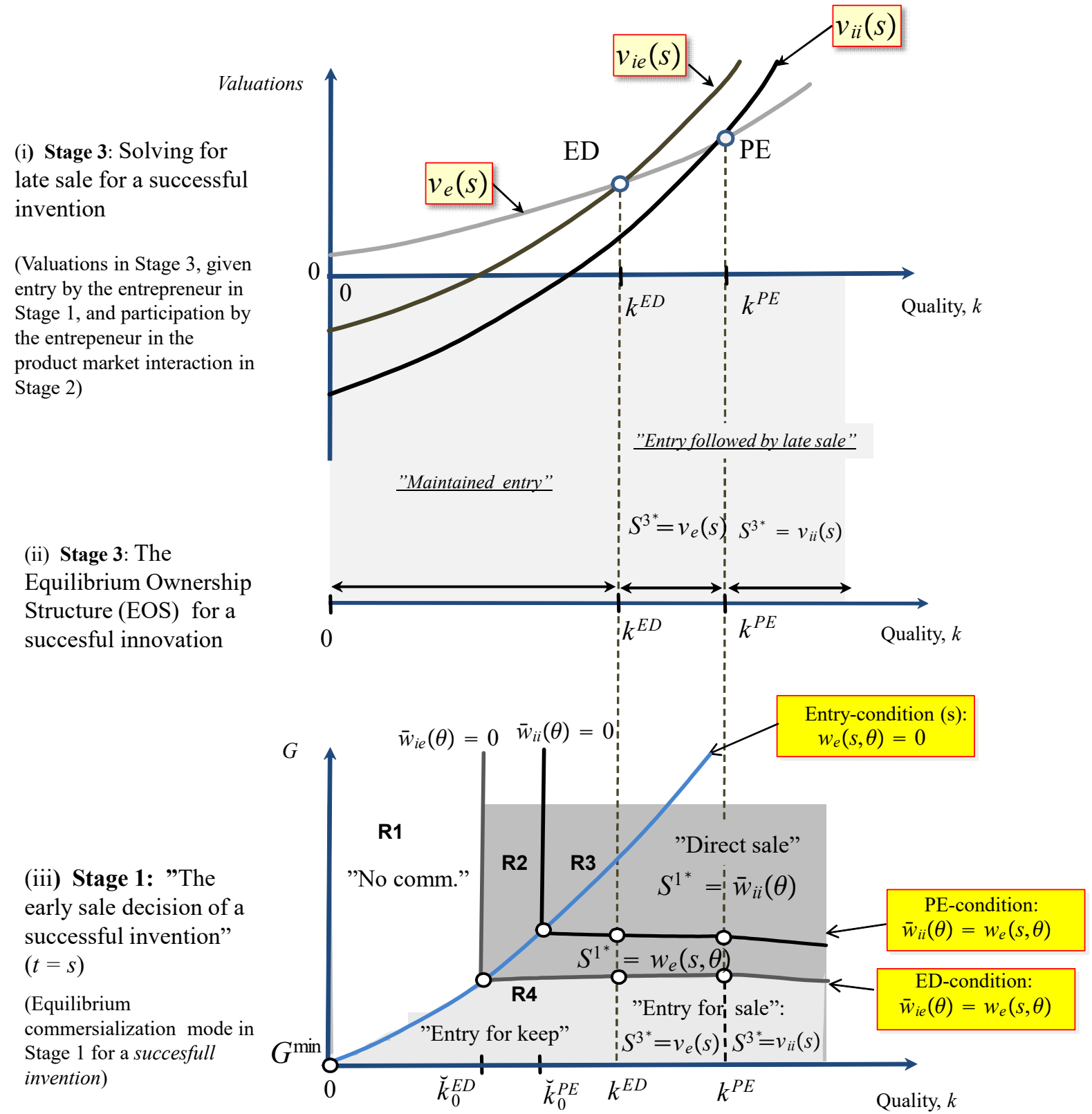

Figure 4.2: Direct sale decision of a successful invention: Note that in Stage 1 it is only the entrepreneur who knows that the invention is successful. The incumbents can only use the prior $\theta$ to assess the probability that the invention is successful. Panels (i) and (ii) solve for the entrepreneur's decision to sell late in Stage 3 given commercialization by entry in stage 1. Panel (iii) shows the entrepreneur's equilibrium commercialization decision in stage 1 in the case that incumbents have a medium prior on the quality of the invention. 


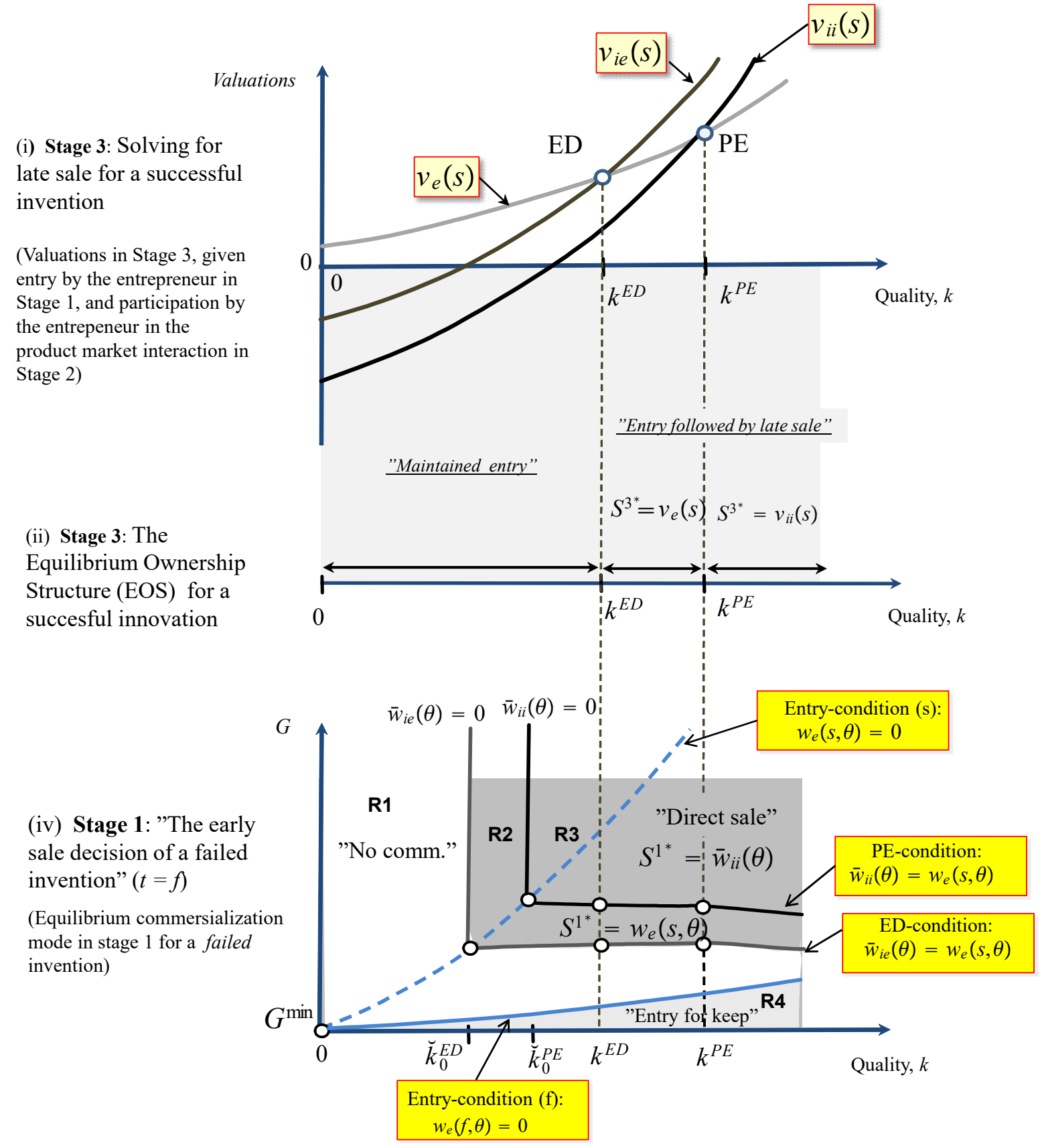

Figure 4.3: Direct sale decision of a failed invention: Note that in Stage 1 it is only the entrepreneur who knows that the invention is a failure. The incumbents can only use the prior $\theta$ to assess the probability that the invention is successful. Panels (i) and (ii) solve for the incumbents' perception of the entrepreneur's decision to sell a successful invention late in Stage 3 , given commercialization by entry in stage 1 . Panel (iii) shows the entrepreneur's equilibrium commercialization decision in stage 1 in the case that incumbents have a medium high prior over that the invention is successful. 
The ED and PE conditions are the L-shaped curves labelled $G^{E D}(k)$ and $G^{P E}(k)$ in panel (iii) of Figure 4.2. These shapes can be understood from the solid upward-sloping locus labelled $G_{t=s}^{\text {Entry }}(k)$. This is the entrepreneur's Entry condition, which shows combinations of invention quality $k$ and entry costs $G$ such that the entrepreneur breaks even when entering in stage 1 to compete in the product markets in stage 2 and stage $4, w_{e}(s, \theta)=0$. From (4.14), we have $G_{t=s}^{\text {Entry }}(k)=v_{e}(s, \theta)+\max \left\{v_{e}(s), v_{i i}(s)\right\}$, which is increasing in $k$ from Assumptions 1 and A3(i).

When entry is not profitable, $G>G_{t=s}^{\text {Entry }}(k)$, the ED condition is simply the invention quality $\breve{k}_{0}^{E D}$ such that the entry-deterring valuation is zero, i.e., $\left.w_{i e}(\theta)\right|_{k=\breve{k}_{0}^{E D}}=0$. Similarly, the PE condition is the invention quality $\breve{k}_{0}^{P E}$ such that the preemptive valuation is zero, i.e., $\left.w_{i i}(\theta)\right|_{k=\breve{k}_{0}^{P E}}=0$. These cut-offs appear as the vertical segments of the ED and PE conditions in Panel (iii). In the presence of significant transaction costs $T, \breve{k}_{0}^{E D}$ and $\breve{k}_{0}^{P E}$ are strictly positive, as incumbents' valuations $w_{i l}(\theta)$ increase in quality $k$ from Definition 1 and Assumption 3(i). ${ }^{7}$ Moreover, $\breve{k}_{0}^{P E}>\breve{k}_{0}^{E D}$ holds from the concentration effect of an acquisition, i.e., $w_{i e}(\theta)>w_{i i}(\theta)$, such that the ED locus is located to the left of the PE locus.

When entry is profitable, $G<G_{t=s}^{\text {Entry }}(k)$, the ED and PE condition attain their flat segments in panel (iii). To obtain the slope of the $\mathrm{ED}$ and $\mathrm{PE}$ conditions, differentiate with respect to $k$ and $G$ and use $w_{e, G}^{\prime}(s, \theta)=-1$ from (4.14):

$$
\frac{d G^{E D}}{d k}=-\left[w_{i e, k}^{\prime}(\theta)-w_{e, k}^{\prime}(s, \theta)\right], \quad \frac{d G^{P E}}{d k}=-\left[w_{i i, k}^{\prime}(\theta)-w_{e, k}^{\prime}(s, \theta)\right], \text { for } G<G_{t=s}^{E n t r y}(k) .
$$

The flat slope of the ED and PE conditions shown in Panel (iii) thus emerges when the net value of incumbents, i.e., $w_{i e}(\theta)-w_{e}(s, \theta)$, is unresponsive to invention quality, i.e., $w_{i l, k}^{\prime}(\theta)-$ $w_{e, k}^{\prime}(s, \theta) \approx 0$. This outcome might be surprising, given how the net value in the late acquisition game in stage 3 must increase in invention quality $v_{i i, k}^{\prime}(s)-v_{e, k}^{\prime}(s)>0$ to induce the entrepreneur to sell at higher invention quality, as shown in Proposition 1 and illustrated in the upper Panels (i) and (ii) of Figure 4.2. In the early acquisition game in stage 1, however, incumbents do not know with certainty the quality of the invention. Intuitively, if their prior $\theta$ is sufficiently low, this will depreciate their willingness to pay for the invention, making their stage- 1 valuations increase on par with the reservation price when the (perceived) invention quality increases. Given the L-shaped ED and PE locus, how does the equilibrium commercialization pattern then materialize? In region R1 in panel (iii), entry costs are too high to make entry profitable. Moreover, invention quality (expected invention quality $\theta k$ ) is too low to compensate for the transaction costs that incumbents face. Thus, the entrepreneur cannot commercialize the invention in this region. In region $\mathrm{R} 2$, we note that $w_{i e}(\theta)>w_{e}(s, \theta)=0>w_{i i}(\theta)$ holds when entry is not profitable, while $w_{i e}(\theta)>w_{e}(s, \theta)>w_{i i}(\theta)>0$ holds when entry is profitable. From the reasoning in the late acquisition game in stage 3 , as the inequality $w_{i e}(\theta)>w_{e}(s, \theta)>w_{i i}(\theta)$ holds, it follows that one incumbent will buy the invention at the reservation price, here $S^{1^{*}}=w_{e}(s, \theta)>\bar{w}_{i i}(\theta)$, where the latter inequality implies that rival incumbents will not challenge this acquisition. In region R3, at higher entry costs, the incumbents' preemptive valuation will exceed the reserva-

\footnotetext{
${ }^{7}$ Assumption 4 tells us how the term $v_{i l}(f, \theta)$ in $(4.22)$ behaves relative to quality $k$. Under reasonable assumptions, however, $v_{i l}(f, \theta)$ terms are non-decreasing in quality.
} 
tion price, $w_{i i}(\theta)>w_{e}(s, \theta)$. Again, symmetric to the interaction in the late auction in stage 3 , a bidding war among incumbents will occur, and the price will be $S^{1^{*}}=w_{i i}(\theta)>w_{e}(s, \theta)$.

What will then happen if entry costs are so low that incumbents' valuations cannot match the entrepreneur's reservation price, $w_{e}(s, \theta)>w_{i e}(\theta)>w_{i i}(\theta)$ ? This case is depicted in region R4 in panel (iii). The entrepreneur will then reject the bids of the incumbents and retain the invention in stage 1 . However, the profits that she and her incumbent rivals generate in the product market interaction in stage 2 verify that the invention is successful and of quality $k>0$. The entrepreneur can now choose to maintain her ownership of the invention - and participate in the full-information product market interaction in stage 4 - or sell it under full information in the stage-3 auction. Panels (i) and (ii) then reiterate the result from proposition 1, where the entrepreneur will sell her invention in stage 3 if it has medium quality, $k \in\left[k^{E D}, k^{P E}\right)$ at the reservation price, $S^{3^{*}}=v_{e}(s)$. However, if the invention has very high quality, $k \in\left[k^{P E}, \bar{k}\right)$, incumbents will bid aggressively over possession, driving the price all the way to the preemptive valuation, $S^{3^{*}}=v_{i i}(s)$. For low invention quality, $k \in\left(0, k^{E D}\right)$, the entrepreneur will retain the invention in stage 3 .

Figure 4.2 thus reveals that invention quality may have different effects on the outcome of the acquisition game under asymmetric information (stage 1) and under full information (stage 3). If the entrepreneur verifies quality by first entering the market and participating in the product market, generating sales and earning profits, she can then sell the invention in a fullinformation auction and increase her reward at high invention quality. However, without such verification, incumbents will be uncertain about the true quality of the invention (as manifested by a medium size of the prior, $\theta$ ): Invention quality will then have an ambiguous effect on the entrepreneur's commercialization choice in stage 1 . If incumbents are very pessimistic (as manifested by a very low prior $\theta$ ), one can show that $w_{i l, k}^{\prime}(\theta)-w_{e, k}^{\prime}(s, \theta)<0$. The ED and PE locuses are then upward-sloping, and higher invention quality would lead to entry in the early stage-1 auction. However, if incumbents hold a very optimistic view (as manifested by a very high prior, $\theta), w_{i l, k}^{\prime}(\theta)-w_{e, k}^{\prime}(s, \theta)>0$ and the ED and PE locuses now slope downwards: Higher invention quality will now induce the entrepreneur to sell directly in the early acquisition game in stage 1.

We can then summarize by stating the following proposition.

Proposition 2. (Direct sale). Suppose that entry is profitable for a successful invention, $w_{e}(s, \theta)>0$. Then, the following holds:

(i) If incumbents' prior over the event that the invention is successful, $\theta$, is sufficiently high, higher (potential) invention quality, $k$, will lead to direct commercialization by sale in stage 1.

(ii) When incumbents' prior over the event that the invention is successful, $\theta$ is sufficiently low, and the entry cost $G$ is not too high, higher quality, $k$, for a successful invention $(t=s)$ will lead to "Entry for Sale": That is, the entrepreneur will choose a sequence of "Entry" in stage 1, followed by "Verification" in stage 2 and then, finally, "Late Sale" in stage 3.

We note that part (ii) of Proposition 2 is a potential explanation for the observation in Figure 3.1 that entrepreneurs sell their best patents post-entry. 
Commercialization of a failed invention $(l=f) \quad$ What if the entrepreneur instead brings a failed invention $(t=f)$ to the commercialization game in stage 1? Figure 4.3 depicts the Equilibrium Ownership Structure for this case. Let us first explore the Entry condition for a failed invention, labelled $G_{t=f}^{\text {Entry }}(k)$. Again, it shows combinations of invention quality $k$ and entry costs $G$ such that the entrepreneur breaks even when entering to compete in the product market in stage 2 and stage $4, w_{e}(f, \theta)=0$. From (4.15), we have $G_{t=f}^{\text {Entry }}(k)=v_{e}(f, \theta)+v_{e}(f)$, which is increasing in $k$ from Assumption 3(i). This may be surprising at first - how can a failed invention create value for the entrepreneur when entering the market in stage 2 ? The reason is the incumbents' belief, $\theta$, that the entrepreneur brings a successful invention into the product market - the entrepreneur exploits this asymmetric information. ${ }^{8}$

Note that the outcome of stage 1 is independent of the type of the invention in regions R2 and R3: Both types of inventions are sold at the reservation price of a successful invention $S^{1^{*}}=w_{e}(s, \theta)$ in region $\mathrm{R} 2$ and at the preemptive valuation $S^{1^{*}}=w_{i i}(\theta)$ in region $\mathrm{R} 3$. As incumbents cannot distinguish between successful and failed inventions in the early acquisition game, an entrepreneur with a failed invention has a lower reservation price than an entrepreneur with a successful invention, $w_{e}(f, \theta)<w_{e}(f, \theta)$, and will gladly sell her failed invention to an incumbent. In fact, she cannot sell at a lower price than $w_{e}(s, \theta)$. This is again the lemons problem: The incumbents know that no entrepreneur that has a successful invention would sell at a price lower than $w_{e}(s, \theta)$, and thus, accepting a price below the reservation price of a successful invention $w_{e}(s, \theta)$ would reveal that the invention is a failure.

Maintaining the assumption of a medium size of the prior such that the ED and PE locus are L-shaped in panel (iii) of Figure 4.3, we note that the region R1 with no commercialization expands with the area under the ED condition. For very low entry costs and increasingly higher (perceived) invention quality in region $\mathrm{R} 4$, the entrepreneur can enter the market, again exploiting the asymmetric information in stage 2. An incumbent who buys a failed invention can also exploit the asymmetric information in stage 2 to gain a strategic advantage.

Thus, we can make the following observations.

Corollary 2. (Failed invention). The following holds:

(i) When entry costs are low, $w_{e}(f, \theta)>0$ or $G \in\left(G^{\min }, G_{t=f}^{\text {Entry }}(k)\right)$, an entrepreneur with a failed invention can use the asymmetric information regarding the quality of the invention to enter the market even if the market is initially entry stable.

(ii) When $w_{i e}(\theta)>w_{e}(s, \theta)>0$ holds, an incumbent who acquires a failed invention from the entrepreneur can use the asymmetric information regarding the true quality of the invention to gain a strategic advantage in the stage-2 product market interaction.

\section{Empirical analysis}

In the empirical analysis, we will derive estimation equations to test the theory and then present the data and the results. Two different decisions are examined by backward induction: (i) the

\footnotetext{
${ }^{8}$ Nevertheless, compared with the entry condition for a successful invention, this gain is limited, as the incumbents will have learned the true type of the invention when the interaction proceeds to stage 4 . This can be seen in panel (iii) where $G_{t=f}^{\text {Entry }}(k)<G_{t=s}^{\text {Entry }}(k)$.
} 
decision to sell an already-commercialized invention (stage 3) and (ii) the early sale decision of an invention that has not yet been proven in the marketplace (stage 1).

\subsection{Estimating the decision to sell late}

Let $R_{E}(l, s)$ be the net revenue or reward that the entrepreneur gets from retaining or selling a successful invention in stage 4 . It follows that the reward is simply the entry value, or the reservation price, $R_{E}(e, s)=v_{e}(s)$, when the entrepreneur chooses to retain the invention for a low invention quality, $k \in\left[\bar{k}, k^{E D}\right)$. However, when preemptive acquisitions occur in the region $k \in\left(k^{P E}, \bar{k}\right)$, the entrepreneur will earn a premium since the reward from selling under bidding competition is strictly higher than what she would earn from retaining it, $R_{E}(i, s)=S^{3^{*}}=$ $v_{i i}(s)>v_{e}(s)$. However, when selling without bidding competition in the region $k \in\left(k^{E D}, k^{P E}\right)$, the reward from commercialization will be the same as when retaining the invention, $R_{E}(i, s)=$ $S^{3^{*}}=v_{e}(s)$.

Using a "random utility framework", we first show that testing the hypothesis that incumbent acquisitions are preemptive against the null hypothesis that acquisitions are entry-deterring essentially corresponds to testing whether the entrepreneur's reward function under sale is significantly different from the reward function when the entrepreneur retains the invention and enters the product market. We then show how this can be done by estimating a simple probit or logit model on data where one only observes the entrepreneur's choice of commercialization mode and underlying characteristics such as the quality of the invention.

Formally, let $R_{e, m}$ be the reward for entrepreneur $e$ choosing commercialization mode $m=$ (Sale, Entry), consisting of the reward $R_{E, m}\left(k_{e}, T_{e}, G_{e}, s\right)$ implied from Proposition 1 and a stochastic term $\varepsilon_{e, m}$, i.e.,

$$
R_{e, m}=R_{E, m}\left(k_{e}, T_{e}, G_{e}, s\right)+\varepsilon_{e, m}, \quad m=(\text { Sale }, \text { Entry }),
$$

where $\varepsilon_{e, m}$ captures idiosyncratic factors affecting entrepreneur $e$ 's choice of commercialization not captured in the theory. In what follows, we assume that the entrepreneur knows the reward function $R_{e, m}$ and its components, while the error term is unknown to the econometrician. The latter could be personal traits of the entrepreneur or environmental factors affecting the entrepreneur that are unobserved.

To proceed, we linearize $R_{E, m}\left(k_{e}, T_{e}, G_{e}, s\right)$ in its components. That is, we approximate the reward function with a function that is linear in invention quality, fixed operating costs, transaction costs and the cost of entry. The reward function may differ depending on the entry mode. Indeed, since $R_{E, E n t r y}\left(k_{e}, T_{e}, G_{e}, s\right)=v_{e}(s)$ under entry, whereas $R_{E, S a l e}\left(k_{e}, T_{e}, G_{e}, s\right)=$ $S^{3^{*}}$ under sale, we have

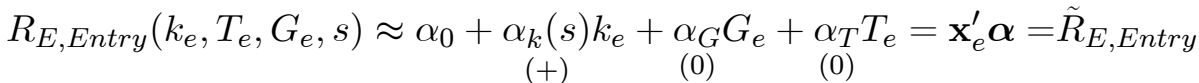

$$
\begin{aligned}
& R_{E, \text { Sale }}\left(k_{e}, T_{e}, G_{e}, s\right) \approx \beta_{0}+\beta_{k} k_{e}+\beta_{G} G_{e}+\beta_{T} T_{e}=\mathbf{x}_{e}^{\prime} \boldsymbol{\beta}=\tilde{R}_{E, \text { Sale }} \\
& \text { (+) (?) (?) }
\end{aligned}
$$

The signs in (5.2) directly follow from (4.6) and Definition 1. The linearized reward function 
under entry $\tilde{R}_{E, \text { Entry }}$ must increase in invention quality, $\alpha_{k}(s)>0$, but decrease in entry costs, $\alpha_{G}<0$, while it is not affected by transaction costs, $\alpha_{T}=0$. Then, we note that if an entrydeterring acquisition takes place at $S^{3^{*}}=v_{e}(s)$, the linearized reward functions under entry and entry-deterring acquisitions in (5.2) and (5.3) must be identical, $\beta=\alpha$, since the entrepreneur is only paid her reservation price.

Figure 5.1 illustrates identification from varying the quality of the invention. The first two panels restate the derivation of the Equilibrium Ownership Structure and equilibrium reward under Lemma 1 in Figure 4.1. In panel (iii) of Figure 5.1, we then graph the linearized reward functions under entry and sale, $\tilde{R}_{E, E n t r y}$ and $\tilde{R}_{E, \text { Sale. }}$. When an entry-deterring acquisition occurs given medium quality at the reservation price $S^{3^{*}}=v_{e}(s)$, the reward functions under entry and sale have an identical slope, $\alpha_{k}$. Hence, their difference in slope must be zero, as indicated by $\gamma_{k}=\beta_{k}-\alpha_{k}(s)=\alpha_{k}(s)-\alpha_{k}(s)=0$ in panel (iii). In contrast, if acquisitions are preemptive, the bidding competition between incumbents drives up the acquisition price to $S^{3^{*}}=v_{i i}(s)>v_{e}(s)$, which implies that the linearized reward functions under sale and entry must now differ, $\boldsymbol{\beta} \neq \boldsymbol{\alpha}$. Panel (iii) also depicts the linearized reward function under bidding competition $\tilde{R}_{E, \text { Sale }}$. Under Proposition 1, we know that the preemptive valuation must increase faster in quality than the reservation price, $v_{i i, k}^{\prime}-v_{e, k}^{\prime}>0$. However, then, the slope of the linearized reward function under bidding competition, $\beta_{k}$, must be larger than the slope of the linearized reward function under entry, $\alpha_{k}$. That is, if acquisitions are preemptive in nature, there must be a positive difference in slope, $\gamma_{k}=\beta_{k}-\alpha_{k}(s)=\beta_{k}(s)-\alpha_{k}(s)>0$, as shown by the angle between $\tilde{R}_{E, S a l e}$ and $\tilde{R}_{E, E n t r y}$ at $k^{P E}$ in panel (iii) of Figure 5.1. This is our main identification condition for preemptive acquisitions.

From (4.5), it also follows that the linearized reward under a preemptive sale $\tilde{R}_{E, \text { Entry }}$ must decrease in transaction costs, $\alpha_{T}<0$, while it is not affected by entry costs, $\beta_{G}=0$. From (5.2) and (5.3), the remaining difference in slopes becomes $\gamma_{T}=\beta_{T}-\alpha_{T}<0$. This gives the additional identification conditions for preemptive acquisitions.

With this information in hand, we proceed to derive the empirical model. The entrepreneur will choose commercialization by sale if her reward under a sale is higher than her reward under entry, $R_{e, \text { Sale }}>R_{e, \text { Entry }}$. Substituting the linear reward functions (5.2)-(5.3) into (5.1), we can then write the probability that the entrepreneur will choose commercialization by sale as

$$
\begin{aligned}
\operatorname{Prob}\left[\text { Sale }_{e}\right] & =\operatorname{Prob}\left[\tilde{R}_{e, \text { Sale }}+\varepsilon_{e, \text { Sale }}>\tilde{R}_{e, \text { Entry }}+\varepsilon_{e, \text { Entry }}\right] \\
& =\operatorname{Prob}\left[\varepsilon_{e, \text { Entry }}-\varepsilon_{e, \text { Sale }}<\mathbf{x}_{e}^{\prime}(\boldsymbol{\beta}-\boldsymbol{\alpha})\right] \\
& =\operatorname{Prob}\left[\varepsilon_{e}<\mathbf{x}_{e}^{\prime} \boldsymbol{\gamma}\right]=\int_{-\infty}^{\mathbf{x}_{e}^{\prime} \boldsymbol{\gamma}} f\left(\varepsilon_{e}\right) d \varepsilon_{e}=F\left(\mathbf{X}_{e}^{\prime} \boldsymbol{\gamma}\right) .
\end{aligned}
$$

Note that the vector $\boldsymbol{\gamma}=\boldsymbol{\beta}-\boldsymbol{\alpha}$ contains the difference in slope between the linearized reward under commercialization by sale under bidding competition and commercialization by entry or commercialization by sale without bidding competition, and $f\left(\varepsilon_{e}\right)$ is the density of the error term, $\varepsilon_{e}=\varepsilon_{e, \text { Entry }}-\varepsilon_{e, \text { Sale }}$. Making assumptions on the structure of the error term, we can then estimate the vector $\gamma$ using maximum likelihood procedures. ${ }^{9}$

\footnotetext{
${ }^{9}$ If $\varepsilon_{e, m}$ is distributed according to the Gumbel distribution, then $\varepsilon_{e}$ will be distributed according to the logistic distribution, and $F\left(\mathbf{x}_{e}^{\prime} \gamma\right)=\Lambda\left(\mathbf{x}_{e}^{\prime} \gamma\right)$, where $\Lambda(\cdot)$ is the cumulative density function of the
} 
(i) Solving for late sale in Stage 3 for a successful invention

(Valuations given entry by the entrepreneur in Stage 1 , followed by her participation in the product market interaction in Stage 2)

(ii) The Equilibrium Ownership Structure (EOS) in stage 3 for a succesful innovation
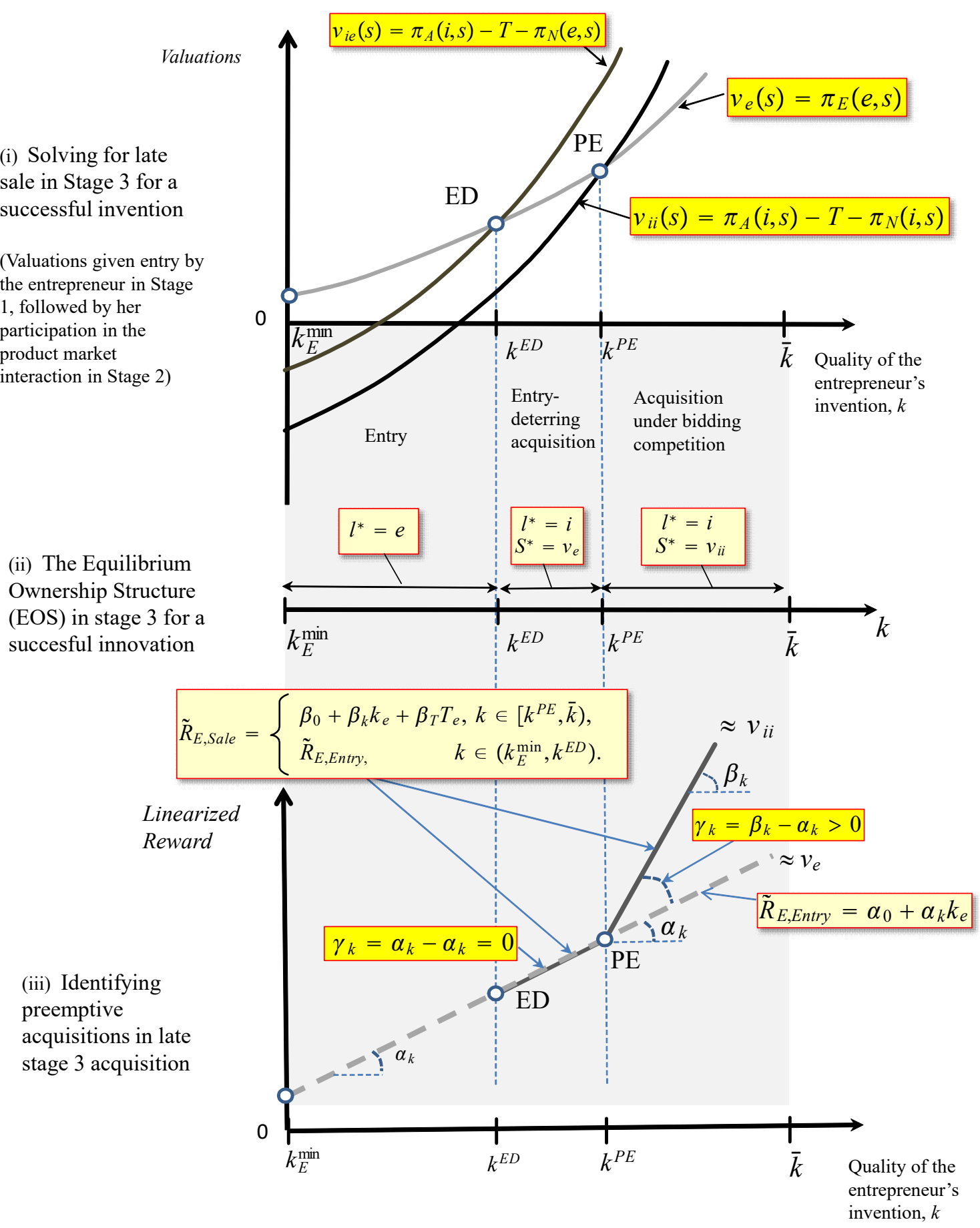

Figure 5.1: Illustrating identification of commercialization under bidding competition. If bidding competition arises, this must imply that the reward function under sale is steeper than under entry, or $\gamma_{k}=\beta_{k}-\alpha_{k}>0$. 
We can now derive a testable hypothesis on the nature of incumbent acquisitions from our proposed model. We have the following proposition:

Proposition 3. Consider entrepreneurs that succeeded in innovating, $t=s$, and then chose to keep the invention in stage 1 and enter the product market interaction under asymmetric information in stage 2. Now, in stage 3, they face the choice between retaining the invention to sustain their entry and compete against incumbents under symmetric information in stage 4 and selling the invention to an incumbent. Then, the following holds:

i. (Entry-deterring acquisitions) If commercialization by sale takes place by entry-deterring acquisition at $S^{3^{*}}=v_{e}(s)$, then $\boldsymbol{\gamma}=\mathbf{0}$, or equivalently, $\boldsymbol{\beta}=\boldsymbol{\alpha}$. This implies

$[\mathbf{a}] \gamma_{k}=\alpha_{k}(s)-\alpha_{k}(s)=0$,

[b] $\gamma_{G}=\alpha_{G}-\alpha_{G}=0$,

[c] $\gamma_{T}=\alpha_{T}-\alpha_{T}=0$.

ii. (Preemptive acquisitions) If commercialization by sale takes place by preemptive acquisition at $S^{3^{*}}=v_{i i}(s)>v_{e}(s)$, then $\boldsymbol{\gamma} \neq \mathbf{0}$, or equivalently, $\boldsymbol{\beta} \neq \boldsymbol{\alpha}$. More precisely,

[a] $\gamma_{k}=\beta_{k}(s)-\alpha_{k}(s)>0$,

[b] $\gamma_{G}=\beta_{G}-\alpha_{G}=0$,

[c] $\gamma_{T}=\beta_{T}-\alpha_{T}<0$.

Summing up the identification strategy, if there are no preemptive acquisitions, the entrepreneur will only receive her reservation price, either when entry or entry-deterring acquisition occur. In the case of preemptive acquisition, the reward will be higher due to bidding competition. Thus, if we can reject the reward functions for sale and entry being equal, $\gamma=\mathbf{0}$, in favour of the alternative of them being different, $\gamma \neq \mathbf{0}$, then the first condition for evidence of preemptive bidding competition is fulfilled (part (ii)). The second condition that must be fulfilled is that the individual parameters $\left(\gamma_{k}=\beta_{k}-\alpha_{k}>0, \gamma_{G}=\beta_{G}-\alpha_{G}=0, \gamma_{\Gamma}=\beta_{\Gamma}-\alpha_{\Gamma}<0\right.$ and $\gamma_{\tau}=\beta_{\tau}-\alpha_{\tau}>0$ ) must have the correct sign (part ii, [a]-[c]). While Proposition 3 is derived under Assumption A1, it also holds if we allow for exits or synergies. This is true since Proposition 3(ii) simply tests for the difference in the slopes of the reward functions.

logistic distribution. When $\varepsilon_{e, m}$ are mean-zero normally distributed, $\varepsilon_{e}$ will also be normally distributed, and $F\left(\mathbf{x}_{e}^{\prime} \gamma\right)=\Phi\left(\mathbf{x}_{e}^{\prime} \gamma\right)$, where $\Phi(\cdot)$ is the cumulative density function of the normal distribution. In either case, parameters $\gamma$ can be estimated by maximizing the likelihood function:

$$
\mathcal{L}=\prod_{e} F\left(\mathbf{x}_{e}^{\prime} \gamma\right)^{m_{e}} F\left(1-\mathbf{x}_{e}^{\prime} \gamma\right)^{1-m_{e}},
$$

where $m_{e}=1$ when commercialization by sale is chosen, and $m_{e}=0$ when commercialization by entry is chosen. 


\subsection{Estimating the decision to sell early}

We can use the same method to derive corresponding predictions for the early sales decision in stage 1. This is straightforward since the early acquisition game is essentially symmetric to the late acquisition stage described by Proposition 2: In a preemptive acquisition, the sales price is an incumbent's preemptive valuation, $S^{1^{*}}=w_{i i}(\theta)$, and in entry-deterring acquisition, the sales price is the reservation price for a successful innovation $S_{\text {Early }}^{*}=w_{e}(s, \theta)$, regardless of the invention type from the lemons problem. The entrepreneur will have a reservation price that depends on whether she has a successful or failed invention, $w_{e}(t, \theta)$.

Linearizing the reward functions in the early sale decision, we have $R_{E, E n t r y}\left(k_{e}, T_{e}, G_{e}, t, \theta\right)=$ $w_{e}(t, \theta)$ under entry and $R_{E, \text { Sale }}\left(k_{e}, T_{e}, G_{e}, t, \theta\right)=S^{1^{*}}$. In the former, we thus do not not know the type of innovation $t$. Linearizing the reward functions, we obtain ${ }^{10}$

$$
\begin{aligned}
& R_{E, E n t r y}\left(k_{e}, T_{e}, G_{e}, t, \theta\right) \approx \alpha_{0}(t, \theta)+\underset{(+)}{\alpha_{k}(t, \theta) k_{e}}+\underset{(-)}{\alpha_{G} G_{e}}+\underset{(0)}{\alpha_{T} T_{e}}=\mathbf{x}_{e}^{\prime} \boldsymbol{\alpha}(t)=\tilde{R}_{E, E n t r y}(t) \\
& R_{E, \text { Sale }}\left(k_{e}, T_{e}, G_{e}\right) \approx \beta_{0}(\theta)+\beta_{k}(\theta) k_{e}+\beta_{G} G_{e}+\beta_{T} T_{e}=\mathbf{x}_{e}^{\prime} \boldsymbol{\beta}(\theta)=\tilde{R}_{E, \text { Sale }} \\
& \text { (+) (?) (?) }
\end{aligned}
$$

Since transaction costs do not affect the reservation price of either type of invention - while entry costs are now in play and have the same impact irrespective of type $-\alpha_{G}<0$ and $\alpha_{T}=0$. From Assumption 4.3, (4.14) and (4.15), a higher quality of the invention $k$ again increases the linearized reward, $\alpha_{k}(t, \theta)>0$. However, since a successful invention increases the possessor's profit more than a failed invention does in stage $4, \alpha_{k}(s, \theta)>\alpha_{k}(f, \theta) .{ }^{11}$

Turning to the linearized reward function under sale, we know that incumbents will either pay their preemptive valuation, $w_{i i}(\theta)$, or the reservation price for a successful innovation, $w_{e}(s, \theta)$. Thus, under a preemptive early sale (when the entrepreneur sells under bidding competition), we have $\beta_{k}(\theta)>0, \beta_{G}=0$ and $\beta_{T}<0$, whereas under an entry-deterring acquisition (the entrepreneur sells without bidding competition), $\beta_{k}(\theta)=\alpha_{k}(s, \theta)>0, \beta_{G}=\alpha_{G}<0$ and $\beta_{T}=\alpha_{T}=0$. Note that due to the lemons problem, this holds regardless of the type of invention.

As illustrated in Figure 4.2 and Figure 4.3, the entrepreneur can also find it optimal to not commercialize the invention. To include the choice of abstaining, let the reward from not commercializing be zero, $R_{E}=0$. Then, let $R_{e, N o}(k, T, G)=R_{E, N o}\left(k_{e}, T_{e}, G_{e}\right)+\varepsilon_{e, N o}$ be the reward for an entrepreneur to choose "No commercialization". The term $R_{E, N o}\left(k_{e}, T_{e}, G_{e}, \theta_{e}\right)=$ 0 can be (trivially) linearized in its arguments to get

$$
R_{e, N o}\left(k_{e}, T_{e}, G_{e}, t\right)=\underset{(0)}{\psi_{0}}+\underset{(0)}{\psi_{k}} k_{r}+\underset{(0)}{\psi_{F}} G_{r}+\underset{(0)}{\psi_{T}} T_{r}=\mathbf{x}_{e}^{\prime} \psi
$$

We can now allow the entrepreneur to choose between "No commercialization (No)", "Entry" and "Direct Sale" in stage 1. Formally, let $m, l=\left(D_{-}\right.$Sale, Entry, No $)$. The probability that the entrepreneur will choose commercialization mode $m$ instead of commercialization mode $l$

\footnotetext{
${ }^{10}$ To save on notation, we use the same notation for the coefficients as in (5.2) and (5.3).

${ }^{11}$ From (4.14) and (4.15), $w_{e}(s, \theta)>w_{e}(f, \theta)$.
} 
is then $\operatorname{Prob}\left[m_{e}\right]=\operatorname{Prob}\left[R_{e, m}>R_{e, l}\right] \forall m \neq l$ or $\operatorname{Prob}\left[m_{e}\right]=\operatorname{Prob}\left[\varepsilon_{e, l}-\varepsilon_{e, m}<R_{E, m}(k, T, G)-\right.$ $\left.R_{E, l}(k, T, G)\right] \forall m \neq l$. Assuming that $\varepsilon_{e, m}$ is distributed according to the Gumbel distribution, $\varepsilon_{e}=\varepsilon_{e, m}-\varepsilon_{e, l}$ will be distributed according to the logistic distribution. Under the assumption that $\varepsilon_{e, N o}, \varepsilon_{e, \text { Sale }}$ and $\varepsilon_{e, E n t r y}$ are not correlated, this gives rise to a multinomial logit model, where

$$
\operatorname{Prob}\left[D_{-} S a l e_{e}\right]=\frac{e^{\mathbf{x}_{e}^{\prime} \boldsymbol{\beta}(\theta)}}{e^{\mathbf{x}_{e}^{\prime} \boldsymbol{\beta}(\theta)}+e^{\mathbf{x}_{e}^{\prime} \boldsymbol{\alpha}(t)}+e^{\mathbf{x}_{e}^{\prime} \boldsymbol{\psi}}}, \quad \operatorname{Prob}\left[\operatorname{Entry}_{e}(t)\right]=\frac{e^{\mathbf{x}_{e}^{\prime} \boldsymbol{\alpha}(t)}}{e^{\mathbf{x}_{e}^{\prime} \boldsymbol{\beta}(\theta)}+e^{\mathbf{x}_{e}^{\prime} \boldsymbol{\alpha}(t)}+e^{\mathbf{x}_{e}^{\prime} \boldsymbol{\psi}}} .
$$

Maximum Likelihood can now be used to estimate $\boldsymbol{\delta}^{D \_S a l e}=\boldsymbol{\beta}(\theta)-\boldsymbol{\psi}$ and $\boldsymbol{\delta}^{\text {Entry }}=\boldsymbol{\alpha}(t)-\boldsymbol{\psi}$, where $\boldsymbol{\psi}=\mathbf{0}$ from (5.8) identifies vectors $\boldsymbol{\beta}(\theta)$ and $\boldsymbol{\alpha}$ from (5.2) and (5.3). Given the identifying assumption of $\boldsymbol{\psi}=0$, Wald tests can be used to test whether $\boldsymbol{\beta}(\theta)=\mathbf{0}, \boldsymbol{\alpha}(t)=\mathbf{0}$ and $\boldsymbol{\beta}(\theta)=$ $\boldsymbol{\alpha}(t)$.

\subsubsection{Early commercialization of a successful invention}

We can now adjust Proposition 3 as follows. If the entrepreneur has a successful invention, we have the following:

Proposition 4. Consider entrepreneurs that have succeeded in innovating, $t=s$, and face a choice in stage 1 among retaining the invention and entering the product market, not using the invention and selling the invention to an incumbent. Then, the following holds:

i. (Entry-deterring acquisitions) If early acquisitions are entry-deterring and take place at price, $S_{\text {Early }}^{*}=w_{e}(s, \theta)$, and since $\boldsymbol{\psi}=\mathbf{0}$,

1.) [a] $\boldsymbol{\delta}^{D \_S a l e}=\boldsymbol{\alpha}(s)-\boldsymbol{\psi}=\boldsymbol{\alpha}(s) \neq \mathbf{0}$ and [b] $\boldsymbol{\delta}^{\text {Entry }}=\boldsymbol{\alpha}(s)-\boldsymbol{\psi}=\boldsymbol{\alpha}(s) \neq \mathbf{0}$,

2.) $\boldsymbol{\delta}^{D \_S a l e}-\boldsymbol{\delta}^{\text {Entry }}=\mathbf{0}$,

3.) $[\mathrm{a}] \delta_{k}^{D \_ \text {Sale }}=\delta_{k}^{\text {Entry }}=\alpha_{k}(s, \theta)>0$, and hence, $\delta_{k}^{D \_ \text {Sale }}-\delta_{k}^{\text {Entry }}=0$, [b] $\delta_{G}^{D \_ \text {sale }}=$ $\delta_{G}^{\text {Entry }}=\alpha_{G}<0$, and hence, $\delta_{G}^{D}{ }^{\text {Sale }}-\delta_{G}^{\text {Entry }}=0$, [c] $\delta_{T}^{D-}{ }^{D a l e}=\delta_{T}^{\text {Entry }}=\alpha_{T}=0$, and hence, $\delta_{T}^{D}{ }^{D}$ sale $-\delta_{T}^{\text {Entry }}=0$.

ii. (Preemptive acquisitions) If an entrepreneur sells early in a preemptive acquisition at price $S_{\text {Early }}^{*}=w_{i i}(\theta)$, and since $\boldsymbol{\psi}=\mathbf{0}$,

1.) $[\mathrm{a}] \boldsymbol{\delta}^{D \_S a l e}=\boldsymbol{\beta}(\theta)-\boldsymbol{\psi}=\boldsymbol{\beta}(\theta) \neq \mathbf{0}$ and $[\mathrm{b}] \boldsymbol{\delta}^{\text {Entry }}=\boldsymbol{\alpha}(s)-\boldsymbol{\psi}=\boldsymbol{\alpha}(s) \neq \mathbf{0}$,

2.) $\boldsymbol{\delta}^{D \_S a l e}-\boldsymbol{\delta}^{\text {Entry }} \neq \mathbf{0}$,

3.) $[\mathrm{a}] \delta_{k}^{D \_ \text {Sale }}=\beta_{k}(\theta)>0, \delta_{k}^{\text {Entry }}=\alpha_{k}(s, \theta)>0$, and hence, $\delta_{k}^{D \_ \text {Sale }}-\delta_{k}^{\text {Entry }} \lesseqgtr 0$, [b] $\delta_{G}^{D-}{ }^{\text {sale }}=\beta_{G}=0, \delta_{G}^{\text {Entry }}=\alpha_{G}<0$, and hence, $\delta_{G}^{D-\text { Sale }}-\delta_{G}^{\text {Entry }}>0,[\mathrm{c}]$ $\delta_{T}^{D-\text { sale }}=\beta_{T}<0, \delta_{T}^{\text {Entry }}=\alpha_{T}=0$, and hence, $\delta_{T}^{D_{-} \text {sale }}-\delta_{T}^{\text {Entry }}<0$.

Similar to Proposition 3, the crucial identification for preemptive acquisitions stems from rejecting $\boldsymbol{\beta}=\boldsymbol{\alpha}(s)$ while failing to reject $\boldsymbol{\beta}(\theta)=\mathbf{0}$ and $\boldsymbol{\alpha}(s)=\mathbf{0}$ (Part ii, 1.) and 2.)). Preemptive acquisitions additionally require $\delta_{G}^{D}{ }^{D}$ sale $=\beta_{G}=0$, i.e., that entry costs do not affect the choice between selling and not commercializing the invention, while higher entry costs should 
lead the entrepreneur to prefer no commercialization over entry, $\delta_{G}^{E n t r y}=\alpha_{G}<0$. Thus, at higher entry costs, the entrepreneur would prefer to sell over entry, $\delta_{G}^{D}{ }^{-}$Sale $-\delta_{G}^{\text {Entry }}>0$ (Part ii, 3b). Moreover, at higher transaction costs, she should prefer no commercialization over selling, $\delta_{T}^{D}{ }^{D}$ sale $=\beta_{T}<0$, while transaction costs should not affect the choice between entry and no commercialization, $\delta_{T}^{\text {Entry }}=\alpha_{T}=0$. Thus, at higher transaction costs, she would the prefer entry over sale, $\delta_{T}^{D-}{ }^{D}$ sale $-\delta_{T}^{\text {Entry }}<0$ (Part ii, 3c).

Importantly, due to asymmetric information regarding quality, preemptive acquisitions are consistent with any sign of $\delta_{k}^{D \_ \text {Sale }}-\delta_{k}^{\text {Entry }}=\beta_{k}(\theta)-\alpha_{k}(s, \theta)$, that is, the impact of higher quality on the choice between entry and sale is ambiguous. The model, however, requires $\beta_{k}(\theta)>0$ and $\alpha_{k}(s, \theta)>0$, and thus, higher quality induces the entrepreneur to choose sale or entry over no commercialization (Part ii, 3a).

\subsubsection{Early commercialization of a failed invention}

What if the entrepreneur then commercializes a failed invention in stage 1? Recall that the incumbent cannot distinguish between a failed and successful invention. We then adjust Proposition 3 as follows.

Proposition 5. Consider entrepreneurs that have failed at innovating, $t=f$, and face a choice in stage 1 among retaining the invention and entering the product market, not using the invention and selling the invention to an incumbent. Then, the following holds:

i. (Entry-deterring acquisitions) If early acquisitions are entry-deterring and take place at price $S_{\text {Early }}^{*}=w_{e}(s, \theta)$, and since $\boldsymbol{\psi}=\mathbf{0}$

1.) $[\mathrm{a}] \boldsymbol{\delta}^{D \_S a l e}=\boldsymbol{\alpha}(s)-\boldsymbol{\psi}=\boldsymbol{\alpha}(s) \neq \mathbf{0}$ and $[\mathrm{b}] \boldsymbol{\delta}^{\text {Entry }}=\boldsymbol{\alpha}(f)-\boldsymbol{\psi}=\boldsymbol{\alpha}(f) \neq \mathbf{0}$,

2.) $\boldsymbol{\delta}^{D \_S a l e} \neq \boldsymbol{\delta}^{\text {Entry }}$,

3.) $[\mathrm{a}] \delta_{k}^{D \_ \text {Sale }}=\alpha_{k}(s, \theta)>0, \delta_{k}^{\text {Entry }}=\alpha_{k}(f, \theta)>0$, and hence, $\delta_{k}^{D \_ \text {Sale }}-\delta_{k}^{\text {Entry }}>0[\mathrm{~b}]$ $\delta_{G}^{D-}{ }^{\text {sale }}=\delta_{G}^{\text {Entry }}=\alpha_{G}<0$, and hence, $\delta_{G}^{D-{ }^{-} \text {sale }}-\delta_{G}^{\text {Entry }}=0,[\mathrm{c}] \delta_{T}^{D-{ }^{\text {sale }}}=\delta_{T}^{\text {Entry }}=$ $\alpha_{T}=0$, and hence, $\delta_{T}^{D-}{ }^{D a l e}-\delta_{T}^{\text {Entry }}=0$.

ii. (Preemptive acquisitions) If an entrepreneur sells early in a preemptive acquisition at price $S_{\text {Early }}^{*}=\bar{w}_{i i}(\theta)$, and since $\boldsymbol{\psi}=\mathbf{0}$

1.) [a] $\boldsymbol{\delta}^{D \_S a l e}=\boldsymbol{\beta}(\theta)-\boldsymbol{\psi}=\boldsymbol{\beta} \neq \mathbf{0}$ and [b] $\boldsymbol{\delta}^{\text {Entry }}=\boldsymbol{\alpha}(f)-\boldsymbol{\psi}=\boldsymbol{\alpha}(f) \neq \mathbf{0}$,

2.) $\boldsymbol{\delta}^{D \_ \text {Sale }} \neq \boldsymbol{\delta}^{\text {Entry }}$,

3.) $[\mathrm{a}] \delta_{k}^{D \_ \text {Sale }}=\beta_{k}(\theta)>0, \delta_{k}^{\text {Entry }}=\alpha_{k}(f, \theta)>0$, and hence, $\delta_{k}^{D \_ \text {Sale }}-\delta_{k}^{\text {Entry }} \lesseqgtr 0$, [b] $\delta_{G}^{D-}{ }^{\text {sale }}=\beta_{G}=0, \delta_{G}^{\text {Entry }}=\alpha_{G}<0$, and hence, $\delta_{G}^{D-}{ }^{\text {sale }}-\delta_{G}^{\text {Entry }}>0,[\mathrm{c}]$ $\delta_{T}^{D}{ }^{\text {sale }}=\beta_{T}<0=\delta_{T}^{\text {Entry }}=\alpha_{T}=0$, and hence, $\delta_{T}^{D \_ \text {sale }}-\delta_{T}^{\text {Entry }}<0$.

Propositions 4 and 5 are qualitatively the same in terms of predicted signs under preemptive acquisitions (c.f. part ii in each proposition). The only difference occurs if a sale occurs without bidding competition, in which case we have $\delta_{k}^{D \_S a l e}-\delta_{k}^{\text {Entry }}=\alpha_{k}(s, \theta)-\alpha_{k}(f, \theta)>0$ under a failed invention (Part i) as illustrated by the entry conditions in panel (iii) in Figure $4.3 .{ }^{12}$

\footnotetext{
${ }^{12}$ This, again, follows from (4.14) and (4.15), such that $w_{e}(s, \theta)>w_{e}(f, \theta)$.
} 


\subsection{Data}

To estimate (5.4) and (5.9), we will use a dataset on patents granted to small firms (fewer than 200 employees) and individual inventors. Most reported sales in the data involved large incumbent acquirers. The dataset is based on a survey of Swedish patents granted in $1998 .{ }^{13}$ In that year, 1082 patents were granted to Swedish small firms and individuals. ${ }^{14}$ Information about inventors, applying firms, their addresses and the application date for each patent was obtained from the Swedish Patent and Registration Office (PRV). Thereafter, a questionnaire was sent out to the inventors of the patents in $2004 .{ }^{15}$ They were asked where the invention was created, if and when the invention had been commercialized, which mode of commercialization was chosen, and the type of financing, among other questions. Of the 1082 inventors, 867 filled out and returned the questionnaire, i.e., the response rate was 80 percent. The non-response was not systematic. ${ }^{16}$ The survey data set was complemented with data on forward citations from www.espacenet.com.

From the theory, we are interested in those patents for which the inventors can decide whether to commercialize the patent. ${ }^{17}$ There are 624 patents in which the inventors have some ownership. Of these 624 patents, 364 were commercialized, that is, a product based on the patent was introduced into the market. Of these 624 patents, 260 were not commercialized. Thus, the commercialization rate is 58 percent; see Table 5.1. ${ }^{18}$ Among the 364 commercialized patents, a rough grouping shows that 91 patents were commercialized by selling or licensing the patent, while 273 were commercialized through entry. Note that a sale of an invention and an exclusive licence of an invention are equivalent in our theory. Since the licensing contracts

\footnotetext{
${ }^{13}$ A further description of the data can be found at http://www.ifn.se/web/Databases_9.aspx and in Svensson (2007).

${ }^{14}$ In 1998, 2760 patents were granted in Sweden. Of these, 776 were granted to foreign firms, 902 to large Swedish firms with more than 1000 employees, and 1082 to Swedish individuals and firms with fewer than 1000 employees. In a pilot survey carried out in 2002, it turned out that large Swedish firms refused to provide information on individual patents. Furthermore, it is impossible to persuade foreign firms to fill out questionnaires about patents. The majority of these foreign firms are large multinationals.

15 Each patent always has at least one inventor and often an applying firm. The inventors or the applying firm can be the owner of the patent, but the inventors can also indirectly be owners of the patent, via the applying firm. Sometimes, the inventors are only employed by the applying firm, which owns the patent. If the patent had several inventors, the questionnaire was sent to one inventor only.

16 The non-response was due to $10 \%$ of the inventors having old addresses, $5 \%$ having correct addresses but nevertheless receiving no response from the inventors and $5 \%$ refusing to reply. The only information we have about the non-respondents is the IPC class of the patent and the region of the inventors. For these variables, there was no systematic difference between respondents and non-respondents.

17 We also undertake estimations in which the entrepreneurial firm has fewer than 100 employees, irrespective of inventor ownership. This yields a sample of 454 commercialized patents. The results remain unchanged when using this different sample. See the Appendix.

18 This rate should be compared to the few available studies that have measured the commercialization of patents: 47 percent for American patents is found by Morgan et al. (2001), and 55 percent is reported in the studies surveyed by Griliches (1990). The higher commercialization rate in the present study is explained by the fact that only patents directly or indirectly owned by the inventors are included - large (multinational) firms have a much larger number of defensive patents. Griliches (1990) confirms this view and reports that the commercialization rate is 71 percent for small firms and inventors.
} 
are almost only exclusive in the data, we treat licence contracts and sales as symmetric in the empirical analysis.

Consistent with the theory, the patents can be commercialized in two different phases early (stage 1) and late (stage 2) - as shown in Table 5.2. However, in the "Early phase", 17 patents were sold directly, 36 were licensed directly, and for 311 patents the inventors entered the market themselves. In the "Late phase", the commercialization mode may change for all commercialized patents except for those 17 patents that were sold directly in the early phase, i.e., 347 patents are then the relevant sample. Of these, 38 patents were sold or licensed, of which 8 patents had previously been licensed and the remaining 30 patents had previously been used by the inventors to enter the market.

\subsubsection{Dependent variable: mode of commercialization}

As the dependent variable, we use the commercialization mode of the patent. When analysing direct sales in the first phase, we consider all 624 observations when estimating (5.9). The dependent variable DirectSale takes value 2 if the patent was sold/licensed directly (53 observations), 1 if the inventor entered the market himself (311 observations), and 0 if there was no commercialization (260 observations).

In (5.4), where we are interested in late sale in the second phase, a binary variable LateSale is defined taking value 1 if the patent was sold or licensed to another firm (38 observations) and 0 if the commercialization mode was not changed (309 observations).

\subsubsection{Measuring the quality of an invention, $k$}

The explanatory variables used in estimating (5.4) are given in Table 5.3. The main variable of interest is the quality of an invention, $k$. To measure $k$, we use the number of forward citations (excluding self-citations) that a patent receives within five years after patent publishing. A higher number of forward citations is thus associated with higher invention quality $k$.

Forward citations are seen as one of the most important quality indicators of patents in the literature (Harhoff et al., 1999; Lanjouw and Schankerman, 1999; Hall et al., 2005). The basic idea of why forward citations measure inherent quality is that competitors in an industry undertake R\&D with similar types of objectives. When rival firms or other entrepreneurs discover new inventions, they will patent them to protect them. When applying for patent protection, inventors will need to cite important previous inventions that are either in the process of applying for patent protection or have approved patent protection. Thus, forward citations indicate downstream $\mathrm{R} \& \mathrm{D}$ efforts.

A previous high-quality invention in a certain industry will be relatively more important for performance in that industry. For example, a high-quality drug patent, which substantially affects competitors' profit flows, should have more citations from future drug patents than from semi-conductor patents. Therefore, we divide all forward citations, $A_{-} C I T$, into two groups: (i) forward citations where the cited and citing patents have at least one common technology class at the four-digit ISIC level, denoted as $W_{-} C I T$, and (ii) forward citations that have no common technology class at the four-digit ISIC level, denoted as B_CIT. 
The 624 patents in the sample combined have 631 forward citations within technologies and 65 between technologies. Most patents (69 percent) have no forward citations within technologies, and cited patents seldom have more than three citations. Among non-commercialized patents, only 22 percent are cited, whereas 35 and 41 percent of the entry and sale patents are cited, respectively.

As can be seen in Table 5.3 (first phase), patents that are not commercialized have the lowest number of forward citations per patent (0.58). Patents that are retained for entry or for entry followed by a later sale/license have a higher number of average citations (1.36) than patents that are directly sold/licensed (1.11). The difference between direct sale/license and entry is not statistically significant, indicating the presence of a lemons problem (Proposition 2).

However, if we study the citation pattern within the group of patents that are initially kept under the control of the inventor (second phase in Table 5.3), a different picture emerges. The average number of forward citations of patents that are sold or licensed post-entry ("late sale/license" $=2.58$ ) is 2.2 times higher than among patents that maintained entry ("keep"=1.18), with the difference being nearly statistically different. This suggests that entry can be used to verify quality and that post-entry entrepreneurs can benefit from selling their invention to incumbents (Proposition 1).

A potential concern in identifying the effect of higher quality on the mode of commercialization in equation (5.4) is reverse causality. For example, forward citations may, in principle, be influenced by the commercialization mode of the patent, i.e., a sale could cause a higher citation rate. However, we argue that this is not a problem of great concern. The reason is that citations are required to be within five years of publication, and many sale/licensing contracts in the data are signed relatively late (4-5 years after patent application).

\subsubsection{Other Explanatory variables}

Entry costs, $G$ To measure the costs of commercialization under entry $G$, we use additive dummies for different firm sizes. Firms that already have marketing, manufacturing and financial resources in-house should have lower costs of entering the market with a new product. We then define the variables $S M A L L$, which takes value 1 for firms with 11-200 employees and 0 otherwise, and MICRO, which equals 1 for micro companies with 2-10 employees and 0 otherwise. Entrepreneurial firms with either of these characteristics should face lower entry costs $G$ than the reference group of inventors without any employees.

Transaction costs, $T$ As a measure of transaction costs, we use the variable $P V C$, the percentage of the R\&D stage that was financed by private venture capitalists or business angels. Gans et al. (2002) find evidence that the involvement of private venture capitalists increased the probability of commercialization by sale. They argue that such agents participate in networks with firms, thereby decreasing the search and transaction costs associated with finding an external buyer, i.e., the presence of a venture capitalist should reduce the transaction cost $T$. 
Additional controls We will also use additive dummies (fixed effects) for technologies and regions and a trend variable for the application year, broadly controlling for unobservable technology-, region- and time-specific factors (including differences in the extent of asymmetric information problems captured in the model by the belief, $\theta$ ). Patents are divided into technology groups based on the patents' IPC classes, according to Breschi et al. (2004). A patent may belong to several different IPC classes. However, it is not possible to determine the main IPC class, as the classes are listed in alphabetical order for each patent in Espacenet (2014). Therefore, a patent in the database used in this study may belong to as many as four different industry classes. Consequently, the 30 industry dummies are not mutually exclusive. ${ }^{19}$ The data are also divided into six different regions, based on the residence of the inventors. Five additive dummies are included for these six groups in the estimations. A trend variable APPLY is also included, measuring the application year.

\subsection{Results}

\subsubsection{Late sale}

Asymmetric information problems are present in the market for inventions when the entrepreneur is better informed about the invention's quality. As shown in the theoretical model, this informational problem can be removed by demonstrating the quality of the invention through the profits and revenues generated by early entry into the product market. After high quality is revealed, Proposition 1 demonstrates that entrepreneurs may sell their best invention under preemptive bidding competition. We now explore the results from estimating the late sale decision.

To estimate late sale, we use the probit model (5.4) derived in Section 5.1. The estimates are shown in Table 5.4, where $L A T E S A L E=1$ for the 38 patents that are first commercialized by entry or licensed and then are sold/licensed, and $L A T E S A L E=0$ for the remaining 309 patents that are commercialized by entry or licensed and remain in the inventor's ownership. Specifications A and B only include the "core variables" that proxy for invention quality $k$ (the citation measures $A_{-}$cit or $W_{-}$cit), entry costs $G$ (firm size, SMALL and MICRO) and transaction costs $T$ (the presence of a private venture capitalist, $P V C$ ). Specification $\mathrm{C}$ adds the measure of between citations, $B \_C I T$, while Specification D also adds the application year, $A P P L Y$. Specification A uses the citation variable $A_{-} C I T$, whereas specifications B-D use $W \_C I T$. All specifications have region- and technology-specific effects.

The estimates are in line with Proposition 3(ii) and give evidence that entrepreneurs can sell their invention under bidding competition post-entry. Regardless of the specification considered, Wald tests reject that late acquisitions are entry-deterring $(\boldsymbol{\gamma}=\mathbf{0}$, or $\boldsymbol{\beta}=\boldsymbol{\alpha})$. In Specification A, the citation variable $A_{-} C I T$ is positive and statistically significant, which supports that incumbents' preemptive valuations post-entry are more responsive than the reservation price of the entrepreneur post-entry, i.e., consistent with $\gamma_{k}=\beta_{k}(s)-\alpha_{k}(s)>0$ in Proposition 3(ii)[a]. Moreover, our proxies for entry costs, SMALL and MICRO, are also insignificant. This is in

\footnotetext{
${ }^{19}$ In some estimations, we have to reduce the number of industry classes because of the limited number of observations in each mode class.
} 
line with Proposition 3(ii)[b], or $\gamma_{G}=\beta_{G}-\alpha_{G}=0$, as earlier entry implies that entry costs are sunk and incumbents' valuations are not influenced by entry costs. However, the insignificant estimate of $P V C$ is not in line with Proposition 3(ii)[c], $\gamma_{T}=\beta_{T}-\alpha_{T}<0$. One reason might be that this variable is an insufficiently precise measure of transaction costs. Specifications B, $\mathrm{C}$ and $\mathrm{D}$ with the within-technology class citation, $W_{-} C I T$, yield similar results.

For robustness, we re-estimate Table 5.4 with a logit specification in Appendix Table A1, again without finding any qualitative changes in the results. The results are also unaffected by adding a number of control variables such as the share of ownership in the entrepreneurial firms held by the inventor and whether the inventor had complementary or more patents.

We then re-estimate Table 5.4 with an extended sample. A possible objection to our sample is that the potential buyer/licensee does not care whether the inventor is the owner of the patent. Instead of using the sample of patents owned by inventors, there is an alternative sample to use when estimating the models - all patents owned by individuals or firms with fewer than 100 employees. This implies that the entrepreneur will be small compared to the incumbent firms, as assumed in the theoretical model. Such a sample has 430 commercialized patents, of which 42 are commercialized by late sale. The Probit model is estimated for the new sample (see the last column of Appendix Table A1). This yields approximately the same result as in Table 5.4. The Wald tests show that there is evidence of preemptive acquisitions in the market for entrepreneurial inventions, and the quality of the invention $(k)$ has significant impacts on the commercialization mode, while there is no effect of entry costs $(G)$.

In sum, we find some initial support for the verification model in which initial entry can remove informational problems and lead to a late sale under bidding competition. We now explore this further by estimating the direct sale decision.

\subsubsection{Direct sale}

To estimate early sale, we use the multinomial logit model (5.9) derived in Section 5.2. We use the same explanatory variables as in the previous section. In all specifications in Table 5.5, the Direct Sale column shows the parameter estimates for the choice between direct sale and no commercialization, the Direct entry column the choice between direct entry and no commercialization, and the Wald column the choice between direct sale and direct entry. Irrespective of specification in Table 5.5, the Wald I tests reject $\boldsymbol{\delta}^{D \_S a l e}=\boldsymbol{\delta}^{\text {Entry }}$, which from part (ii) in Propositions 4 and 5 suggests that early, direct acquisitions are also preemptive in nature. Exploring this further, the Wald II tests reveal that $\boldsymbol{\delta}^{D}$ Sale $=0$ and $\boldsymbol{\delta}^{\text {Entry }}=0$ can also be rejected. Turning to the individual estimates, we have evidence for $\delta_{k}^{D}{ }^{\text {Sale }}=\beta_{k}(\theta)>0$ and $\delta_{k}^{\text {Entry }}=\alpha_{k}(t, \theta)>0$, noting that the citation variables $A_{-} C I T$ and $W_{-} C I T$ are positive and statistically significant in Table 5.5 when comparing Direct Sale to No commercialization and when comparing Direct Entry to No commercialization. However, we cannot reject the equality of the estimates for $A \_C I T$ and $W \_C I T$ for the Direct Sale equation or Direct Entry equation, which suggests that $\delta_{k}^{\bar{D}}{ }^{\text {Sale }}-\delta_{k}^{\text {Entry }}=\beta_{k}(\theta)-\alpha_{k}(t, \theta)=0$. These results indicate the presence of asymmetric information in line with the Equilibrium Ownership Structure arising from the L-shaped ED and PE conditions in panel (iii) of Figure 4.2 and Figure 4.3. In these figures, we discussed how this result arises when the incumbents' prior of a successful invention, $\theta$, was of 
an intermediate size. The lemons effect then weakens the response in incumbent valuations to higher invention quality. An increase in the perceived quality of an invention $k$ then increases incumbents' valuations on par with the entrepreneur's reservation price. ${ }^{20}$

Turning to the proxies for entry costs, SMALL and MICRO, entrepreneurs with firms should have lower entry costs $G$ than the reference group of entrepreneurs that have no firm. Starting with the Entry equation in Table 5.5, we note that both variables are positive and significant: Hence, this is consistent with $\delta_{G}^{\text {Entry }}=\alpha_{G}<0$. Inconsistent with our theory, we find that the variable $S M A L L$ is negative and significant in the SALE equation. However, when testing the difference in these estimates between Direct sale and Direct entry, the associated Wald test rejects the null hypothesis. This result is consistent with the presence of bidding competition in direct acquisitions from Proposition $4(\mathrm{ii}) 3[\mathrm{~b}], \delta_{G}^{D}{ }^{-}$Sale $-\delta_{G}^{\text {Entry }}>0$. Finally, the variable $P V C$, which measures involvement by venture capitalists, is positive and significant in the Direct Sale equation - but not in the Direct entry equation. The null hypothesis of equal coefficient estimates in the sale and entry equations for the PVC variable is also rejected at the 10 percent level in all specifications. These results are consistent with Proposition 4(ii) 3[c] and the presence of asymmetric information in the direct sale decision. ${ }^{21}$ Again, the results in Table 5.4 on Late sale suggest that early entry can remove this asymmetric information problem.

\section{Concluding remarks}

We have shown that a significant share of the sales of patented Swedish inventions takes place after the inventor has entered the product market. Product market entry is used as a verification mechanism for high-quality inventions. Selling inventions before entry is associated with asymmetric information problems, meaning that the price will be too low for entrepreneurs with high-quality inventions. These entrepreneurs will then use an entry-for-sale strategy to mitigate the information problems and sell their high-quality invention under bidding competition post-entry. Only high-quality inventions will generate a sufficient premium when selling, and thus, the other side of the coin is that inventors with low-quality inventions have to retain their inventions and start mediocre but long-run viable firms themselves.

The paper has important implications for both entrepreneurs and incumbents. First, entrepreneurs with high-quality inventions have a strong incentive to enter the product market to credibly signal the market value of their invention. For example, they may undertake small-scale entry into local markets, working with intermediaries that specialize in marketing and distribution, and get their product into some retailers' stock. They may also seek support from angels or venture capital firms and use these investors' experience to verify the market value of their invention. Moreover, the price premium for high-quality inventions implies that entrepreneurs have a strong incentive to pursue risky projects that lead to high-quality inventions if successful.

However, incumbents have an incentive to avoid post-entry bidding competition, as the price will be higher than that of an early acquisition. In particular, incumbents may end up in a coordination failure: All incumbents would benefit from early acquisition, but the acquirer

\footnotetext{
${ }^{20} \delta_{k}^{D-\text { Sale }}-\delta_{k}^{\text {Entry }}=\beta_{k}(\theta)-\alpha_{k}(t, \theta)=0$ also rejects the presence of entry-deterring acquisitions of failed inventions, which from Proposition 5(i) would imply that $\delta_{k}^{D-}{ }^{D a l e}-\delta_{k}^{\text {Entry }}=\alpha_{k}(s, \theta)-\alpha_{k}(f, \theta)>0$.

${ }^{21}$ This is consistent with $\delta_{T}^{D_{-}}$sale $=\beta_{T}<0$, and $\delta_{T}^{D_{-}}{ }^{\text {sale }}-\delta_{T}^{\text {Entry }}=\beta_{T}-\alpha_{T}<0$.
} 
would need to pay the price under uncertainty. In such a situation, no early acquisition would take place, and subsequently, incumbents may later participate in a bidding war over a highquality target, a bidding war that everyone would lose except the target firm.

Most countries provide various support schemes for start-ups and small businesses that cover all stages of the firms' development and range from initial research grants to the provision of subsidized loans and state guarantees. Financial support and cheap credit in the marketing stage is an important part of this package, to overcome asymmetric information in credit markets. However, entrepreneurs can typically only take advantage of subsidized loans when they enter the market themselves. These provisions imply that many countries in Europe and elsewhere grant fiscal advantages to entrepreneurs who market their inventions themselves, rather than selling out to an incumbent firm. In the United States, for example, one of the main programmes to promote small businesses is the Technological Innovation Programme (TIP), which subsidizes the commercialization of successful prototypes with up to USD 3 million. This support scheme is available only if the SME markets the product itself, or is the leading company in a joint venture (OECD, 2010, p. 106). See OECD (2010) for a listing of similar support schemes for SMEs in all OECD member states. The results derived in this paper suggest that such policies can be sensible if combined with policies that improve the post entry mergers \& acquisitions market. The reason is that reducing the cost of selling inventions may not only have a direct positive effect on the reward for entrepreneurship, but doing so may also create incentives for entry to verify the market value of inventions, which may further increase the incentives for high-quality entrepreneurial research.

A potential concern in identifying the effect of higher quality on the mode of commercialization is reverse causality. Forward citations may be influenced by a patent's mode of commercialization, i.e., a sale could cause a higher citation rate. However, we would expect this not to be a problem of great concern. The reason is that citations are required to be within five years of publication, and many sale/licensing contracts in the data are signed relatively late (4-5 years after patent application).

In the analysis, we have assumed that the seller can only sell the innovation (or the innovative firm) exclusively to one buyer. In many cases, the "innovation" consists of a combination of assets in terms of capital, intellectual capital, and human capital, which cannot be used simultaneously by many firms. Indeed, only 2 of the 48 licensed patents in the dataset have multiple licences.

It is useful to discuss the opposite case in which incumbents have an informational advantage over the entrepreneur, under the assumption that the entrepreneur does not know the true quality of the invention. It then follows that if the invention fails, entry is not profitable, and incumbents do not provide any bids. If the invention is a success, incumbents will have a positive value of acquiring the invention. Then, if the incumbents place positive bids below the reservation price of a successful invention, the entrepreneurs will infer that the invention is successful and reject these bids. Consequently, we are back to the baseline model, and our main analysis is valid. 


\section{References}

[1] Akerlof, G.A., 1970, "The Market for 'Lemons': Quality Uncertainty and the Market Mechanism", Quarterly Journal of Economics, Vol. 84(3), pp. 488-500.

[2] Allain, M. L., Henry, E., and Kyle, M. 2015, "Competition and the Efficiency of Markets for Technology". Management Science, 62(4), 1000-1019.

[3] Anton, J.J. and Yao, D.A., 1994, "Expropriation and Invention: Appropriable rents in the absence of property rights", American Economic Review, Vol. 84(1), pp. 190-209.

[4] Bond, E.W, 1982, "A Direct Test of the "Lemons" Model: The Market for Used Pickup Trucks", American Economic Review, Vol. 72(4), pp. 836-840.

[5] Breschi, S., Lissoni, F. and Malerba, F., 2004, "The Empirical Assessment of Firms' Technological Coherence: Data and Methodology", in Cantwell, J., Gambardella, A. and Granstrand, O. (eds.), The Economics and Management of Technological Diversification, Routledge, London.

[6] Coad, A., Daunfeldt, S. O., Hölzl, W., Johansson, D., and Nightingale, P., 2014,."Highgrowth firms: introduction to the special section.", Industrial and Corporate Change, 23(1), 91-112.

[7] Commission of the European Communities., 2008), Think Small First. A "Small Business Act" for Europe. Communication COM (2008) 394. Brussels. http://ec.europa.eu/enterprise/policies/sme/small-business-act/index_en.htm

[8] Gale, D., and M. Hellwig, 1985, "Incentive-compatible debt contracts:the one-period problem" The Review of Economic Studies, 52, 647-63.

[9] Gans, J.S., Hsu, D.H. and Stern, S., 2002, "When does Start-Up Innovation Spur the Gale of Creative Destruction?", RAND Journal of Economics, Vol. 33(4), pp. 571-586.

[10] Gans, J.S., Hsu., D.H. and Stern, S., 2008. "The impact of uncertain intellectual property rights on the market for ideas: Evidence from patent grant delays", Management Science 54, 982-997.

[11] Gans, J.S. and Stern, S., 2003, "The product market and the market for ideas: Commercialization strategies for technology entrepreneurs",. Research Policy, 32(2), 333-350.

[12] Gans, J.S. and Stern, S., 2000, "Incumbency and R\&D Incentives: Licensing the Gale of Creative Destruction", Journal of Economics and Management Strategy, Vol. 9(4), pp. 485-511.

[13] Genesove, D., 1993, "Adverse Selection in the Wholesale Used Car Market", Journal of Political Economy, Vol. 101(4), pp. 644-665.

[14] Gilbert, .R., 2006, "Looking for Mr. Schumpeter: Where Are We in the CompetitionInnovation Debate?", in Jaffe, A.B., Lerner, J. and Stern, S. (eds.), Innovation Policy and the Economy, Vol. 6, pp. 159-215, MIT Press, Cambridge and London. 
[15] Gilligan, T.W., 2004, "Lemons and Leases in the Used Business Aircraft Market", Journal of Political Economy, Vol. 112(5), pp. 1157-80.

[16] Griliches, Z., 1990, "Patent Statistics as Economic Indicators: A Survey", Journal of Economic Literature, Vol. 28(4), pp. 1661-1707.

[17] Hall, B.H., 1990, "The Impact of Corporate Restructuring on Industrial Research and Development", Brookings Papers on Economic Activity, Special issue 1990, pp. 85-124.

[18] Hall, B.H., Jaffe, A.B. and Trajtenberg, M., 2005, "Market Value and Patent Citations", RAND Journal of Economics, Vol. 36(1), pp. 16-38.

[19] Harhoff, D., Narin, F., Scherer, F.M. and Vogel, K., 1999, "Citation Frequency and the Value of Patented Inventions", Review of Economics and Statistics, Vol. 81(3), pp. 511-515.

[20] Hegde, Deepak, and Hong Luo. "Patent Publication and the Market for Ideas" Working Paper, February 2016. (Accepted for publication in Management Science.)

[21] Hellmann, T. and E. Perotti, 2011. "Circulation of ideas: Firms versus markets". Management Science 57, 1813-1826.

[22] Jehiel, P. and Moldovanu, B, 2006, "Allocative and Informational Externalities in Auctions and Related Mechanisms", in The Proceedings of the 9th World Congress of the Econometric Society, edited by Richard Blundell, Whitney Newey, and Torsten Persson, Cambridge University Press.

[23] Jehiel, P., Moldovanu, B., and Stacchetti, E., 1996, "How (Not) to Sell Nuclear Weapons," American Economic Review, Vol. 86, pp. 814-829.

[24] Jehiel, P, Moldovanu, B. and Stacchetti, E., 1999, "Multidimensional Mechanism design for auctions with externalities." Journal of Economic Theory, 85, pp. 258-293.

[25] Jensen, R. A., J. G. Thursby, and M. C. Thursby, 2003,." The disclosure and licensing of university inventions",.International Journal of Industrial Organization, 21(9), 1271-1300.

[26] Lanjouw, J.O. and Schankerman, M., 1999, "The Quality of Ideas: Measuring Innovation with Multiple Indicators", NBER Working paper No. 7345, Cambridge, MA.

[27] Luo, H., 2014, "When to Sell Your Idea: Theory and Evidence from the Movie Industry", Management Science, 60, no. 12, 3067-3086.

[28] Morgan, R.P., Kruytbosch, C. and Kannankutty, N., 2001, "Patenting and Invention Activity of U.S. Scientists and Engineers in the Academic Sector: Comparisons with Industry", Journal of Technology Transfer, Vol. 26(1-2), pp. 173-183.

[29] Norbäck, P and Persson, L, 2012,"Entrepreneurial Innovations, Competition and Competition Policy" European Economic Review, Vol. 56, No. 3, 2012, 488-506.

[30] Norbäck, P., Persson, L., and Svensson, R., 2016, "Creative Destruction and Productive Preemption", Journal of Business Venturing, Vol. 31, Issue 3, May: 326-343. 
[31] OECD., 2010), SMEs, entrepreneurship and innovation. Paris.

[32] Serrano, C, 2010, "The dynamics of the transfer and renewal of patents", RAND Journal of Economics, Vol. 41, No. 4, pp. 686-708

[33] Svensson, R., 2007, "Commercialization of Patents and External Financing during the R\&D-Phase", Research Policy, Vol. 36(7), pp. 1052-1069.

[34] Townsend, R.M., 1979, "Optimal contracts and competitive markets with costly state verification", Journal of Economic Theory, 21, pp. 265-93.

\section{Appendix: The linear Cournot model}

\subsection{Stage 4: Product market under full information}

The oligopoly interaction is Cournot competition with homogenous goods. The product market profit is $\pi_{i}=\left(P-c_{i}\right) q_{i}$, and firms face inverse demand $P=a-Q$, where $a>0$ is a demand parameter and $Q=\sum_{i=1}^{n} q_{i}$ is aggregate output. Access to the invention reduces the marginal cost. The first-order condition takes the form $\partial \pi_{i} / \partial q_{i}=P-c_{i}-q_{i}^{*}=0$. Making a distinction between firm types, we have

$$
c_{A}(s)=c_{E}(s)=c-k, \quad c_{N A}(t)=c=c_{h}(f), h=\{A, E\}
$$

which can be solved for optimal quantities under entry and sale. Let $q_{h}^{*}(l, t)$ be the output of a firm of type $h=\{A, E, N\}$ under ownership $l=\{i, e, 0\}$ when the invention is of type $t=\{s, f\}$ and $q_{-h}^{*}(l, t)$ be the output of its competitors. Reduced-form profits are

$$
\pi_{h}(l, t)=\left[q_{h}^{*}(l, t)\right]^{2}
$$

since the FOC (written in firm types) $\partial \pi_{h} / \partial q_{h}=0$ implies that $P-c_{h}=q_{h}^{*}(l, t)$. It is straightforward to solve for the equilibrium outputs without the invention present $(l=0)$ and under sale $(l=i)$ and entry $(l=e)$ when the invention has succeeded or failed $t=\{s, f\}$

$$
\begin{aligned}
q_{A}^{*}(i, s) & =\frac{\Lambda+n k}{n+1}, q_{N}^{*}(i, s)=\frac{\Lambda-k}{n+1}, q_{E}^{*}(e, s)=\frac{\Lambda+(n+1) k}{n+2}, q_{N}^{*}(e, s)=\frac{\Lambda-k}{n+2} \\
q_{A}^{*}(i, f) & =\frac{\Lambda}{n+1}=q_{N}^{*}(i, f), q_{E}^{*}(e, f)=\frac{\Lambda}{n+2}=q_{N}^{*}(e, f), \\
q_{N}^{*}(0) & =\frac{\Lambda}{n+1}
\end{aligned}
$$

where $\Lambda=a-c$.

Proof of Definition 1 and the ranking of product market profits From (7.2-(7.4), it it easy to check whether Definition 1 holds and that the rankings in (4.2) and (4.3) hold. 


\subsection{Stage 3: Proof of Proposition 1}

$k^{E D}$ is defined from $v_{i e}\left(k^{E D}, s, \cdot\right)=v_{e}\left(k^{E D}, s, \cdot\right)$ and $k^{P E}$ is defined from $v_{i i}\left(k^{P E}, s, \cdot\right)=$ $v_{e}\left(k^{P E}, s, \cdot\right)$. Using (7.2)-(7.4) in (4.4)-(4.6), we obtain for $G=T=0$

$$
\begin{aligned}
k^{E D} & =\frac{n^{2}-2}{6 n+3 n^{2}+2} \Lambda<\Lambda, \quad k^{P E}=\frac{n+1}{3 n+5} \Lambda<\Lambda, \\
k^{P E}-k^{E D} & =2(n+2) \frac{2 n+3}{(3 n+5)\left(6 n+3 n^{2}+2\right)}>0
\end{aligned}
$$

where $\pi_{N}(l)=0$ for $k=\Lambda=a-c$. Further, note that $v_{i e}(s)-v_{e}(s)=-\frac{n^{2}-2}{(n+2)^{2}(n+1)^{2}} \Lambda^{2}<0$ for $k=0$ and that $v_{i e}(s)-v_{i i}(s)=(\Lambda-k)^{2} \frac{2 n+3}{(n+2)^{2}(n+1)^{2}}>0$.

\subsection{Stage 2: Proof of Assumption 3}

Let us solve the for the Bayes-Nash equilibrium in the product market interaction in stage 3 . Let $P(l, t)=a-Q(l, t)$ be the inverse demand, where $Q(l, t)=\sum_{j=1}^{N(l)} q_{j}(l, t)$. In the Bayes-Nash equilibrium, firms maximize the following direct profits:

$$
\begin{aligned}
\pi_{h}(\cdot, l, s) & =[P(l, s)-(c-k)] q_{h}(l, s) \\
\pi_{h}(\cdot, l, f) & =[P(l, f)-c] q_{h}(l, f) \\
\bar{\pi}_{N}(l) & =\theta \underbrace{P[(l, s)-c] q_{N}(l)}_{\pi_{N}(\cdot, l, s)}+(1-\theta) \underbrace{[P(l, f)-c] q_{N}(l)}_{\pi_{h}(\cdot, l, f)}
\end{aligned}
$$

where, again, non-acquiring incumbents do not know the true quality of the invention.

The first-order conditions are

$$
\begin{aligned}
\frac{\partial \pi_{h}(\cdot, l, s)}{\partial q_{h}(l, s)} & =[P(l, f)-c] q_{h}(l, f)-q_{h}(l, s)=0 \\
\frac{\partial \pi_{h}(\cdot, l, f)}{\partial q_{h}(l, f)} & =[P(l, f)-c]-q_{h}(l, f)=0 \\
\frac{\partial \bar{\pi}_{N}(l)}{\partial q_{N}(l)} & =\theta[P(l, s)-c]+(1-\theta)[P(l, f)-c]-q_{N}(l)=0
\end{aligned}
$$

The Bayes-Nash equilibrium can then be solved as

$$
\begin{aligned}
q_{h}^{*}(l, s, \theta) & =\frac{\Lambda+k-(N(l)-1) q_{N}^{*}(l, \theta)}{2} \\
q_{h}^{*}(l, f, \theta) & =\frac{\Lambda-(N(l)-1) q_{N}^{*}(l, \theta)}{2} \\
q_{N}^{*}(l, \theta) & =\frac{\Lambda-\theta k}{N(l)+1}
\end{aligned}
$$

Note that (7.6) and (7.9) imply a reduced-form profit $\pi_{h}(l, s, \theta)=\left[q_{h}^{*}(l, s, \theta)\right]^{2}$ for $h=A, E$ and (7.7) and (7.10) implies a reduced-form profit $\pi_{h}(l, f, \theta)=\left[q_{h}^{*}(l, f, \theta)\right]^{2}$ for $h=A, E$.

From (7.12) and (7.13), it then follows that $\pi_{h}(l, s, \theta)>\pi_{h}(l, f, \theta)$ for $h=A, E$.

Let $P(l, t, \theta)=a-Q^{*}(l, t, \theta)$ and note that $P(l, s, \theta)-P(l, f, \theta)=-\frac{k}{2}$. Note that $\pi_{N}(l, s, \theta)=$ $[P(l, s, \theta)-c)] q_{N}^{*}(l, \theta)$ and that $\pi_{N}(l, f, \theta)=[P(l, f, \theta)-c] q_{N}^{*}(l, \theta)$. It follows that $\pi_{N}(l, f, \theta)-$ $\pi_{N}(l, f, \theta)=[P(l, f, \theta)-P(l, s, \theta)] q_{N}^{*}(l, \theta)=\frac{k}{2} q_{N}^{*}(l, \theta)>0$. Further, for $h=A, E, \pi_{h}(l, f, \theta)-$ 
$\pi_{N}(l, f, \theta)=[P(l, f, \theta)-c]\left[q_{h}^{*}(l, f, \theta)-q_{N}^{*}(l, f, \theta)\right]>0$, as $q_{h}^{*}(l, f, \theta)-q_{N}^{*}(l, \theta)=\frac{\theta k}{2} \geq 0$. Hence, we have shown that

$$
\pi_{h}(l, s, \theta)>\pi_{h}(l, f, \theta)>\pi_{N}(l, f, \theta)>\pi_{N}(l, s, \theta) \text { for } h=A, E
$$

Note that (7.12) and (7.13) implies that $\frac{d \pi_{h}(l, t, \theta)}{d k}>0$ for $h=A, E$. Moreover, we have that

$$
\begin{aligned}
& \frac{d P(l, s, \theta)}{d k}=-\frac{1}{2}\left[1-\theta \frac{N(l)-1}{N(l)+1}\right]<0 \\
& \frac{d P(l, f, \theta)}{d k}=\frac{\theta}{2} \frac{N(l)-1}{N(l)+1}>0
\end{aligned}
$$

Then, $\frac{d \pi_{N}(l, s, \theta)}{d k}=\frac{d P(l, s, \theta)}{d k} q_{N}^{*}(l, \theta)+[P(l, s, \theta)-c] \frac{d q_{N}^{*}(l, \theta)}{d k}<0$, as $\frac{d q_{N}^{*}(l, \theta)}{d k}<0$ and $\frac{d P(l, s, \theta)}{d k}<0$. It also follows that $\frac{d \pi_{h}(l, t, \theta)}{d k}-\frac{d \pi_{N}(l, t, \theta)}{d k}=\frac{d P(l, f, \theta)}{d k}\left[q_{h}^{*}(l, f, \theta)-q_{N}^{*}(l, \theta)\right]+[P(l, s, \theta)-c]\left(\frac{d q_{h}^{*}(l, f, \theta)}{d k}-\frac{d q_{N}^{*}(l, \theta)}{d k}\right)>$ 0 since $\frac{d P(l, f, \theta)}{d k}>0, q_{h}^{*}(l, f, \theta)>q_{N}^{*}(l, \theta)$ and $\frac{d q_{h}^{*}(l, f, \theta)}{d k}>\frac{d q_{N}^{*}(l, \theta)}{d k}$ from (7.16), (7.13) and (7.14).

\subsection{Stage 1: Proof of Lemma 2}

Note that if incumbents are certain that the invention is successful $(\theta=1)$, Assumption A2 implies that

$$
w_{i l, k}^{\prime}(1)-w_{e, k}^{\prime}(s, 1)=v_{i l, k}^{\prime}(s, 1)-v_{e, k}^{\prime}(s, 1)+v_{i l, k}^{\prime}(s)-v_{e, k}^{\prime}(s)>0,
$$

since $v_{i l, k}^{\prime}(s, 1)-v_{e, k}^{\prime}(s, 1)=v_{i l, k}^{\prime}(s)-v_{e, k}^{\prime}(s)>0$.

If incumbents are certain that the invention is unsuccessful $(\theta=0)$, we have

$$
w_{i l, k}^{\prime}(0)-w_{e, k}^{\prime}(s, 0)=\left\{\begin{array}{l}
-\left[v_{e, k}^{\prime}(s, 0)+v_{e, k}^{\prime}(s)\right]<0 \text { for } k \in\left[0, \breve{k}_{0}^{P E}\right) \\
-\left[v_{e, k}^{\prime}(s, 0)+v_{i i, k}^{\prime}(s)\right]<0 \text { for } k \in\left[\breve{k}_{0}^{P E}, k^{\max }\right)
\end{array}\right.
$$

noting that $v_{e, k}^{\prime}(s)>0$ and $v_{i i, k}^{\prime}(s)>0$ while $w_{i l, k}^{\prime}(0)=0$ and $v_{e, k}^{\prime}(s, 0)>0$ from Assumption A4. Since the prior $\theta \in[0,1]$ is continuous, there must exist a cut-off prior $\tilde{\theta}$ such that $w_{i l, k}^{\prime}(\tilde{\theta})-$ $w_{e, k}^{\prime}(s, \tilde{\theta})=0$ for $k \in\left[\breve{k}_{0}^{P E}, k^{\max }\right)$. For any $\theta=\tilde{\theta}+\varepsilon$, we then have $w_{i l, k}^{\prime}(\theta)-w_{e, k}^{\prime}(s, \theta)>0$, and for any $\theta=\tilde{\theta}-\varepsilon, w_{i l, k}^{\prime}(\theta)-w_{e, k}^{\prime}(s, \theta)<0$. 
Table 5.1 Commercialization mode across firm sizes, number of patents and percent.

\begin{tabular}{lcccc}
\hline \hline $\begin{array}{l}\text { Kind of firm where invention } \\
\text { was created }\end{array}$ & $\begin{array}{c}\text { Total number } \\
\text { of patents }\end{array}$ & $\begin{array}{c}\text { Percent latest } \\
\text { commercialized in 2003 }\end{array}$ & $\begin{array}{c}\text { Percent } \\
\text { Entry }\end{array}$ & $\begin{array}{c}\text { Percent } \\
\text { Sale }\end{array}$ \\
\hline \hline $\begin{array}{l}\text { Small firms (11-200 employees) } \\
\text { Micro companies (2-10 employees) }\end{array}$ & 102 & $70 \%$ & $63 \%$ & $7 \%$ \\
\cline { 2 - 5 } \begin{tabular}{l} 
Individuals (1-4 inventors) \\
\cline { 2 - 5 }
\end{tabular} & 122 & $72 \%$ & $57 \%$ & $16 \%$ \\
\hline \hline Total & 624 & $51 \%$ & $35 \%$ & $16 \%$ \\
\hline
\end{tabular}

Table 5.2. Commercialization mode in Early (Direct) and Late phase, number of patents.

\begin{tabular}{|c|c|c|c|c|}
\hline \multirow[b]{2}{*}{ Early (Direct) phase } & \multicolumn{3}{|c|}{ Late phase } & \multirow[b]{2}{*}{ Total } \\
\hline & No change & Sale & License & \\
\hline No Commercialization & 260 & $\begin{array}{l}---- \\
\end{array}$ & $\begin{array}{l}--- \\
-1\end{array}$ & 260 \\
\hline Entry & 273 & 26 & 4 & 303 \\
\hline Sale & 17 & ---- & ---- & 17 \\
\hline License & 36 & 5 & 3 & 44 \\
\hline Total & 576 & 31 & 7 & 624 \\
\hline
\end{tabular}


Table 5.3. Explanatory variables and basic statistics.

\begin{tabular}{|c|c|c|c|c|c|c|c|c|}
\hline \multirow[b]{2}{*}{$\begin{array}{l}\text { Variable } \\
\text { Name }\end{array}$} & \multirow[b]{2}{*}{ Variable description } & \multirow[b]{2}{*}{$\begin{array}{l}\text { Measure } \\
\text { of: }\end{array}$} & \multirow[b]{2}{*}{$\begin{array}{l}\text { All patents } \\
(\mathrm{n}=624)\end{array}$} & \multicolumn{3}{|c|}{ "Early (Direct) phase } & \multicolumn{2}{|c|}{ Late phase } \\
\hline & & & & $\begin{array}{c}\text { Direct } \\
\text { Sale/license } \\
(n=53)\end{array}$ & $\begin{array}{l}\text { Entry/ } \\
\text { keep } \\
(\mathrm{n}=311)\end{array}$ & $\begin{array}{l}\text { No com- } \\
\text { mercialization } \\
(n=260)\end{array}$ & $\begin{array}{c}\text { Late } \\
\text { sale/license } \\
(n=38)\end{array}$ & $\begin{array}{c}\text { Keep } \\
(\mathrm{n}=309)\end{array}$ \\
\hline A_CIT & $\begin{array}{l}\text { Number of forward citations five } \\
\text { years after publication }\end{array}$ & $k$ & $\begin{array}{c}1.11 \\
(3.09)\end{array}$ & $\begin{array}{l}1.15 \\
(2.97)\end{array}$ & $\begin{array}{c}1.48 \\
(3.81)\end{array}$ & $\begin{array}{c}0.68 \\
(1.85)\end{array}$ & $\begin{array}{c}2.68 \\
(5.15)\end{array}$ & $\begin{array}{l}1.29 \\
(3.54)\end{array}$ \\
\hline$W_{-} C I T$ & $\begin{array}{l}\text { Number of forward citations } \\
\text { within technologies five years } \\
\text { after publication }\end{array}$ & $k$ & $\begin{array}{c}1.01 \\
(2.98)\end{array}$ & $\begin{array}{c}1.11 \\
(2.93)\end{array}$ & $\begin{array}{c}1.36 \\
(3.75)\end{array}$ & $\begin{array}{c}0.58 \\
(1.56)\end{array}$ & $\begin{array}{c}2.58 \\
(5.11)\end{array}$ & $\begin{array}{c}1.18 \\
(3.47)\end{array}$ \\
\hline SMALL & $\begin{array}{l}\text { Dummy which equals } 1 \text { for } \\
\text { small firms (11-200 employees), } \\
\text { and } 0 \text { otherwise }\end{array}$ & $G$ & $\begin{array}{c}0.16 \\
(0.36)\end{array}$ & $\begin{array}{c}0.02 \\
(0.14)\end{array}$ & $\begin{array}{c}0.21 \\
(0.41)\end{array}$ & $\begin{array}{c}0.12 \\
(0.32)\end{array}$ & $\begin{array}{c}0.16 \\
(0.37)\end{array}$ & $\begin{array}{c}0.19 \\
(0.40)\end{array}$ \\
\hline MICRO & $\begin{array}{l}\text { Dummy which equals } 1 \text { for } \\
\text { micro firms ( } 2-10 \text { employees), } \\
\text { and } 0 \text { otherwise }\end{array}$ & $G$ & $\begin{array}{c}0.20 \\
(0.40)\end{array}$ & $\begin{array}{c}0.19 \\
(0.39)\end{array}$ & $\begin{array}{c}0.25 \\
(0.43)\end{array}$ & $\begin{array}{c}0.13 \\
(0.34)\end{array}$ & $\begin{array}{c}0.24 \\
(0.43)\end{array}$ & $\begin{array}{c}0.25 \\
(0.43)\end{array}$ \\
\hline$P V C$ & $\begin{array}{l}\text { Percentage of R\&D-phase } \\
\text { financed by private venture } \\
\text { capitalist }\end{array}$ & $\Gamma$ & $\begin{array}{c}3.17 \\
(13.9)\end{array}$ & $\begin{array}{c}9.11 \\
(25.6)\end{array}$ & $\begin{array}{c}2.47 \\
(11.21)\end{array}$ & $\begin{array}{c}2.79 \\
(13.2)\end{array}$ & $\begin{array}{c}1.66 \\
(7.40)\end{array}$ & $\begin{array}{c}3.25 \\
(14.0)\end{array}$ \\
\hline$B \_C I T$ & $\begin{array}{l}\text { Number of forward citations } \\
\text { between technologies five years } \\
\text { after publication }\end{array}$ & & $\begin{array}{c}0.10 \\
(0.41)\end{array}$ & $\begin{array}{c}0.04 \\
(0.19)\end{array}$ & $\begin{array}{c}0.12 \\
(0.42)\end{array}$ & $\begin{array}{c}0.10 \\
(0.44)\end{array}$ & $\begin{array}{c}0.11 \\
(0.39)\end{array}$ & $\begin{array}{c}0.11 \\
(0.40)\end{array}$ \\
\hline$A P P L Y$ & Year patent was filed & & $\begin{array}{l}1995 \\
(1.7)\end{array}$ & $\begin{array}{l}1995 \\
(1.4)\end{array}$ & $\begin{array}{l}1995 \\
(1.7)\end{array}$ & $\begin{array}{l}1995 \\
(1.6)\end{array}$ & $\begin{array}{l}1995 \\
(2.4)\end{array}$ & $\begin{array}{l}1995 \\
(1.6)\end{array}$ \\
\hline
\end{tabular}


Table 5.4. Results of the probit model with late sale

Dependent variable $=$ LATE SALE

Explanatory

Statistical model: Binomial probit model

variables

Specification B $\quad$ Specification C

Specification D

A_CIT

Specification A Specification B Specification C

(0.024)

W_CIT

$0.060 * *$

$(0.025)$

$0.060 * *$

$0.062 * *$

SMALL

$-0.180$

$-0.178$

$(0.025)$

(0.026)

$(0.268)$

(0.268)

$-0.177$

$-0.221$

MICRO

$-0.098$

$-0.085$

(0.268)

(0.268)

(0.232)

PVC

$-0.011$

(0.231)

$-0.064$

$-0.053$

$-0.011$

$(0.232)$

$(0.235)$

(6.7 E-3)

(6.7 E-3)

(6.7 E-3)

$-0.010$

B_CIT

$-0.113$

(6.5 E-3)

APPLY

(0.167)

$-0.113$

(0.164)

$-0.082$

(0.060)

\begin{tabular}{lcccc}
\hline Technology FE & Yes & Yes & Yes & Yes \\
Region FE & Yes & Yes & Yes & Yes \\
\hline Log Likelihood & -104.1 & -104.0 & -103.9 & -102.7 \\
Wald $\chi^{2}$ I & 29.4 & 29.6 & 31.2 & $37.7 *$ \\
Wald $\chi^{2}$ II & $8.31 *$ & $8.51 *$ & $8.57 *$ & $8.52 *$ \\
\hline
\end{tabular}

Note: The number of observations is 347. LATESALE equals 1 for 38 observations. ***, ** and * indicate significance at the 1,5 and 10 percent level. Standard errors clustered on the inventor are given in parentheses. Parameter estimates for intercept, technology and region dummies are not shown, but are available from the authors upon request. The Wald $\chi^{2} I$ test tests the hypothesis $\gamma=\mathbf{0}$ in Proposition 3. The Wald $\chi^{2}$ II test repeats this for the core variables $A_{-} C I T / W_{-} C I T, S M A L L, M I C R O$. 
Table 5.5. Results of the multinomial logit model with direct sale

\begin{tabular}{|c|c|c|c|c|c|c|}
\hline \multirow{3}{*}{$\begin{array}{l}\text { Explanatory } \\
\text { variables }\end{array}$} & \multicolumn{6}{|c|}{ Multinomial logit model with "No commercialization" as the base alternative } \\
\hline & \multicolumn{3}{|c|}{ Specification A } & \multicolumn{3}{|c|}{ Specification B } \\
\hline & $\begin{array}{c}\text { DIRECT } \\
\text { SALE }\end{array}$ & $\begin{array}{c}\text { DIRECT } \\
\text { ENTRY }\end{array}$ & $\begin{array}{l}\text { Wald } \chi^{2} \\
\text { (diff) }\end{array}$ & $\begin{array}{c}\text { DIRECT } \\
\text { SALE }\end{array}$ & $\begin{array}{c}\text { DIRECT } \\
\text { ENTRY }\end{array}$ & $\begin{array}{l}\text { Wald } \chi^{2} \\
\text { (diff) }\end{array}$ \\
\hline A_CIT & $\begin{array}{c}0.145 * * \\
(0.061)\end{array}$ & $\begin{array}{c}0.109 * * \\
(0.047)\end{array}$ & 0.64 & & & \\
\hline$W_{-} C I T$ & & & & $\begin{array}{c}0.174 * * * \\
(0.066)\end{array}$ & $\begin{array}{c}0.134 * * \\
(0.053)\end{array}$ & 0.75 \\
\hline SMALL & $\begin{array}{c}-2.15 * * \\
(1.06)\end{array}$ & $\begin{array}{c}1.02 * * * \\
(0.29)\end{array}$ & $9.09 * * *$ & $\begin{array}{c}-2.15 * * \\
(1.06)\end{array}$ & $\begin{array}{c}1.02 * * * \\
(0.29)\end{array}$ & $9.05 * * *$ \\
\hline MICRO & $\begin{array}{c}0.31 \\
(0.43)\end{array}$ & $\begin{array}{c}1.15 * * * \\
(0.27)\end{array}$ & $3.93 * *$ & $\begin{array}{c}0.32 \\
(0.43)\end{array}$ & $\begin{array}{c}1.15 * * * \\
(0.27)\end{array}$ & $3.88 * *$ \\
\hline$P V C$ & $\begin{array}{l}0.018 * * \\
(9.3 \mathrm{E}-3) \\
\end{array}$ & $\begin{array}{c}1.9 \mathrm{E}-3 \\
(8.9 \mathrm{E}-3) \\
\end{array}$ & $2.88 *$ & $\begin{array}{l}0.019 * * \\
(9.3 \mathrm{E}-3)\end{array}$ & $\begin{array}{c}2.1 \mathrm{E}-3 \\
(8.9 \mathrm{E}-3) \\
\end{array}$ & $2.89 *$ \\
\hline Technology FE & & Yes & & & Yes & \\
\hline Regional FE & & Yes & & & Yes & \\
\hline Log likelihood & & -537.8 & & & -536.8 & \\
\hline I. Wald $\chi^{2}$ & $632.7 * * *$ & $46.0 * *$ & $440.8 * * *$ & $608.1 * * *$ & $47.5 * *$ & $424.3 * * *$ \\
\hline II. Wald $\chi^{2}$ & $14.2 * * *$ & $31.4 * * *$ & $16.2 * * *$ & $15.5 * * *$ & $32.7 * * *$ & $16.3 * * *$ \\
\hline
\end{tabular}

Table 5.5. Results of the multinomial logit model with direct sale (continued)

\begin{tabular}{|c|c|c|c|c|c|c|}
\hline \multirow{3}{*}{$\begin{array}{l}\text { Explanatory } \\
\text { variables }\end{array}$} & \multicolumn{6}{|c|}{ "Multinomial logit model with "No commercialization" as the base alternative } \\
\hline & \multicolumn{3}{|c|}{ Specification $\mathrm{C}$} & \multicolumn{3}{|c|}{ Specification D } \\
\hline & $\begin{array}{c}\text { DIRECT } \\
\text { SALE }\end{array}$ & $\begin{array}{c}\text { DIRECT } \\
\text { ENTRY }\end{array}$ & $\begin{array}{l}\text { Wald } \chi^{2} \\
\text { (diff) }\end{array}$ & $\begin{array}{c}\text { DIRECT } \\
\text { SALE }\end{array}$ & $\begin{array}{c}\text { DIRECT } \\
\text { ENTRY }\end{array}$ & $\begin{array}{l}\text { Wald } \chi^{2} \\
\text { (diff) }\end{array}$ \\
\hline$W_{-} C I T$ & $\begin{array}{c}0.206 * * * \\
(0.069)\end{array}$ & $\begin{array}{c}0.164 * * * \\
(0.057)\end{array}$ & 0.88 & $\begin{array}{c}0.207 * * * \\
(0.069)\end{array}$ & $\begin{array}{c}0.163 \text { *** } \\
(0.057)\end{array}$ & 0.99 \\
\hline SMALL & $\begin{array}{c}-2.05 * \\
(1.06)\end{array}$ & $\begin{array}{c}1.04 * * * \\
(0.28)\end{array}$ & $8.53 * * *$ & $\begin{array}{c}-2.05 * \\
(1.06)\end{array}$ & $\begin{array}{c}1.04 * * * \\
(0.28)\end{array}$ & $8.54 * * *$ \\
\hline$M I C R O$ & $\begin{array}{c}0.40 \\
(0.43)\end{array}$ & $\begin{array}{c}1.19 * * * \\
(0.27)\end{array}$ & $3.44 *$ & $\begin{array}{c}0.41 \\
(0.43)\end{array}$ & $\begin{array}{c}1.19 * * * \\
(0.27)\end{array}$ & $3.45 *$ \\
\hline$P V C$ & $\begin{array}{l}0.020 * * \\
(9.4 \mathrm{E}-3)\end{array}$ & $\begin{array}{l}2.6 \mathrm{E}-3 \\
(8.9 \mathrm{E}-3)\end{array}$ & $3.11 *$ & $\begin{array}{l}0.020 * * \\
(9.3 \mathrm{E}-3)\end{array}$ & $\begin{array}{c}2.4 \text { E-3 } \\
(8.9 \text { E-3) }\end{array}$ & $3.28 *$ \\
\hline B_CIT & $\begin{array}{c}-1.10 * \\
(0.58)\end{array}$ & $\begin{array}{l}-0.35 \\
(0.25)\end{array}$ & & $\begin{array}{l}-1.06 \\
(0.57)\end{array}$ & $\begin{array}{l}-0.35 \\
(0.25)\end{array}$ & \\
\hline$A P P L Y$ & & & & $\begin{array}{l}-0.080 \\
(0.089)\end{array}$ & $\begin{array}{c}0.016 \\
(0.054)\end{array}$ & \\
\hline Technology FE & & Yes & & & Yes & \\
\hline Regional FE & & Yes & & & Yes & \\
\hline Log likelihood & & -534.6 & & & -533.9 & \\
\hline I. Wald $\chi^{2}$ & $569.2 * * *$ & $51.3 * * *$ & $407.9 * * *$ & $642.1 * * *$ & $51.4 * *$ & $461.8 * * *$ \\
\hline II. Wald $\chi^{2}$ & $17.8 * * *$ & $35.7 * * *$ & $15.9 * * *$ & $18.3 * * *$ & $35.7 * * *$ & $16.4 * * *$ \\
\hline
\end{tabular}

Note : The number of observations equals 624, of which $M O D E=2$ (direct sale/licensing) for 53 observations and $M O D E=1$ (entry) for 311 observations. 260 observations are classified as "No commercialization" $(M O D E=0)$. Standard errors clustered on the inventor are given in parentheses. ***, ** and $*$ indicate significance at the 1,5 and 10 percent level. Parameter estimates for intercept, technology and region dummies are not shown, but available from the authors upon request.

The Wald $\chi^{2}$ I test tests the hypothesis $\beta(\theta)=\alpha$ in Proposition 4 . The Wald $\chi^{2}$ II test repeats this for the core variables $W_{-} C I T, S M A L L, M I C R O$ and $P V C$. 
Table A1. Results of the model with late sale. Robustness tests.

\begin{tabular}{|c|c|c|c|c|}
\hline \multirow{3}{*}{$\begin{array}{l}\text { Explanatory } \\
\text { Variables }\end{array}$} & \multicolumn{4}{|c|}{ Dependent variable $=$ LATE SALE } \\
\hline & \multirow[b]{2}{*}{ Logit model } & \multicolumn{3}{|c|}{ Probit model } \\
\hline & & \multicolumn{2}{|c|}{ Extra covariates } & Large sample \\
\hline \multirow[t]{2}{*}{$W_{-} C I T$} & $0.113 * * *$ & $0.066 * * *$ & $0.051 * *$ & $0.077 * * *$ \\
\hline & $(0.044)$ & $(0.024)$ & $(0.023)$ & $(0.029)$ \\
\hline \multirow[t]{2}{*}{$S M A L L$} & -0.25 & -0.074 & -0.14 & -0.40 \\
\hline & $(0.52)$ & $(0.28)$ & $(0.29)$ & $(0.25)$ \\
\hline \multirow[t]{2}{*}{ MICRO } & -0.033 & 0.067 & 0.027 & -0.054 \\
\hline & $(0.48)$ & $(0.25)$ & $(0.26)$ & $(0.22)$ \\
\hline \multirow[t]{2}{*}{$P V C$} & -0.017 & $-8.4 \mathrm{E}-3$ & -0.011 & $-9.5 \mathrm{E}-3$ \\
\hline & $(0.013)$ & $(6.5 \mathrm{E}-3)$ & $(6.1 \mathrm{E}-3)$ & $(6.0 \mathrm{E}-3)$ \\
\hline \multirow{2}{*}{ B_CIT } & -0.15 & -0.13 & -0.16 & -0.17 \\
\hline & $(0.31)$ & $(0.17)$ & $(0.18)$ & $(0.17)$ \\
\hline \multirow[t]{2}{*}{$A P P L Y$} & -0.13 & -0.081 & -0.087 & $-0.091 *$ \\
\hline & $(0.12)$ & $(0.060)$ & $(0.061)$ & $(0.054)$ \\
\hline \multirow[t]{2}{*}{$P C T$} & & $9.0 \mathrm{E}-3 *$ & $0.011 * *$ & \\
\hline & & $(5.4 \mathrm{E}-3)$ & $(0.058)$ & \\
\hline \multirow[t]{2}{*}{ KOMPL } & & & $0.58 * *$ & \\
\hline & & & $(0.23)$ & \\
\hline Technology FE & Yes & Yes & Yes & Yes \\
\hline Region FE & Yes & Yes & Yes & Yes \\
\hline Log Likelihood & -102.8 & -101.4 & -98.6 & -118.4 \\
\hline Wald, $\chi^{2}$ I & 37.1 & $39.2 *$ & $43.5 *$ & 36.9 \\
\hline Wald, $\chi^{2}$ II (Core var.) & $8.6 *$ & $8.6 *$ & 7.3 & $10.9 * *$ \\
\hline No. of observations & 347 & 347 & 347 & 430 \\
\hline
\end{tabular}

Note: SALE equals 1 for 38 observations in the small sample and for 42 observations in the large sample. $* * *, * *$ and $*$ indicate significance at the 1,5 and 10 percent level. Standard errors clustered on the inventor are given in parentheses. Parameter estimates for constants, technology and region dummies are not shown, but available from the authors upon request. The Wald $\chi^{2}$ I test tests the hypothesis $\gamma=0$ in Proposition 3. The Wald $\chi^{2}$ II test repeats this for the core variables W_CIT, SMALL, MICRO and PVC. 